\title{
A New Method for Solving the Problem of Determining the Characteristics of Spatial Stiffness and Elasticity of the Rail Threads and Stresses and Strains in Rails
}

\author{
Eduard Danilenko*, Vitalii Molchanov* \\ Department of Railway Track and Track Facilities, State University of Infrastructure and Technology, Kyiv, Ukraine
}

Email address:

tpdanilei@ukr.net (E. Danilenko), zkks@ukr.net (V. Molchanov)

${ }^{*}$ Corresponding author

\section{To cite this article:}

Eduard Danilenko, Vitalii Molchanov. A New Method for Solving the Problem of Determining the Characteristics of Spatial Stiffness and Elasticity of the Rail Threads and Stresses and Strains in Rails. American Journal of Traffic and Transportation Engineering. Special Isssue: Railway Track and Railway Structures. Vol. 6, No. 3, 2021, pp. 58-80. doi: 10.11648/j.ajtte.20210603.12

Received: May 12, 2021; Accepted: June 1, 2021; Published: June 21, 2021

\begin{abstract}
The reference data given in technical literature on the characteristics of spatial stiffness and elasticity of rail threads in the conditions of joint action on the rails of vertical and horizontal lateral forces and torsion are very different and in some cases contradictory. This situation is due to the lack of an accurate analytical solution to this problem and the provision for reference materials only experimental research data, which are clearly different, not only for different railway structures, but also significantly differ in different conditions of acting external forces $\left(P, H, M_{t o r}\right)$. The purpose of this article is to present a new method of analytical solution of the problem of determining the spatial characteristics of stiffness and elasticity of rail threads and also computation the stresses and strains that occur in them, under conditions of complex joint action on rail threads of vertical and horizontal dynamic forces $\left(P_{d y n}, H_{d y n}\right)$ simultaneously with the external torque moment $M_{\text {tor }}$ arising from off-center forces applied to the rails from wheel loads. The complex method of solving the problem was used in the paper. It includes the theoretical part and the results of the experiment. Using the experimental researches characteristics of horizontal lateral stiffness of the rail threads of the head and sole at different constructions of the modern rail fastenings was measured. The second task of determination of the real values of the characteristics of spatial elasticity and stiffness modulus of the rail thread under joint vertical and lateral horizontal bends of the rail in conjunction with its simultaneous torsion was solved by the theoretical methods As the results of author's researches were obtained new values of the characteristics of spatial stiffness and elasticity modulus of rail threads under joint vertical and lateral horizontal bends of the rail in conjunction with its simultaneous torsion. These characteristics were obtained for the modern railway track constrictions with rails (R65, R50, UIC60) on concrete and wooden sleepers and with rail fastenings unlined or lined types (KB, KPP-5, KPP-1, D0). And also these characteristics were obtained in the functional dependence on the ratio of vertical and horizontal lateral forces $P / H$.
\end{abstract}

Keywords: Rail Thread, Stiffness, Elasticity, Torsion, Vertical Forces, Horizontal Forces, Stresses, Strains

\section{Introduction}

When designing a railway track, it is necessary to perform calculations and predict possible stresses and deformations in the rails and other elements of the track structure under the action of rolling stock wheels.

For this purpose as a rule apply engineering calculations of a track on durability. But in the existing calculation methods that are used on many railways $[1,2,3,4]$, the vertical dynamic force $P_{d y n}$ from the wheels of rolling stock is usually considered as the main acting force on the rail. In this case, taking into account other acting forces on the rail (ie transverse lateral forces $H_{d y n}$, or horizontal longitudinal forces $H_{x-x}$, or torques moments $M_{t o r}$ from the eccentrically applied forces) in the calculations is usually not taken into account directly, but in some cases it taken into account by individual coefficients (so-called impact factor $\langle f i\rangle$ ).

However, in many cases, these coefficients are not accurately confirmed for the dynamic forces actually acting on the rails, do not take into account the correct characteristics of the spatial elasticity of rail threads, and do not take into 
account the resistance of rail fasteners of different constructions, and thus, the values of stresses and strains obtained by the existing calculation methods differ significantly from the same magnitudes, that are obtained in experimental studies of the rail threads, of the rail threads, especially in curved sections of track. Thus, in the end, the current method of track calculations for strength does not allow to obtain sufficiently accurate results of deformations and stresses in the rail threads under the actual wheel loads, especially in difficult conditions of joint action on the rail vertical and horizontal dynamic forces $P_{d y n}$ and $H_{d y n}$.

Examples of comparing results of determining the stress in the rail R50 and R65, obtained by theoretical calculations and by experimental measurements, are given at the end of this article (for different operating conditions).

\section{Analysis of Previous Researches and Statement of the Problem}

But with the full formulation of the analytical solution of the problem of calculating the strength of the railway track, which aims to determine the exact values of deformations and stresses in the head and sole of the rails, it is necessary to take into account the effect on the rail thread of all external forces and it is necessary to consider in connection the whole complex of spatial deformations in the rail thread, namely: vertical and horizontal bending of the rail thread, bending of the head and sole relative to the neck of the rail and also rotation of the rail relative to the longitudinal axis $X$ from the action of eccentrically applied forces $P_{d y n}$ and $H_{d y n}$. These deformations and stresses of rail threads in analytical calculations can be determined with sufficient accuracy only by a complete solution of the problem, provided that the characteristics of the spatial elasticity of rail threads, also determined with sufficient accuracy.

The characteristics of the spatial elasticity of the rail thread include: stiffness in the vertical and horizontal planes, and the stiffness of the rail thread during torsion $\left(\beta_{z}, \beta_{y}, \beta_{\varphi}\right)$, as well as functionally related modules of elasticity of the subrail base in the vertical and horizontal planes (lateral and longitudinal) and the modulus of elasticity in torsion $\left(U_{z}, U_{y}, U_{\varphi}\right)$. In this case, it is especially important for accurate analytical calculations to find the correct functional relationships between the external forces acting on the rail thread from the wheels of the rolling stock and the resulting deformations and stresses in this rail thread, taking into account all the characteristics of the spatial elasticity of the rail thread and particular characteristics of rail fasteners of different constructions. However, as already mentioned, a common feature of all the characteristics of stiffness and elasticity given in technical literature at lateral bending and torsion of the rail thread (for any track structures) is the lack of functional dependence of these characteristics on the actual dynamic vertical and horizontal forces $P_{d y n}$ and $H_{d y n}$.

Our modern experimental and theoretical researches in 2012-2016 [5, 6, 7] established the actual existence of a direct functional dependence of the real values of stiffness and modulus of elasticity of the rail thread during lateral bending and torsion from the vertical and horizontal wheel loads acting on the rail and in addition, it was found that this dependence, cause a real influence on the variability of the characteristics of stiffness and elasticity of the rail threads in the lateral plane and during torsion, depending on the ratio $P_{d y n} / H_{d y n}$.

$$
\begin{aligned}
& \beta_{y}^{(f r)}=f_{1}\left(P_{\mathrm{d} y n} / H_{d y n}\right) ; \quad \beta_{\phi}^{(f r)}=f_{2}\left(P_{\mathrm{d} y n} / H_{d y n}\right) ; \\
& U_{y}^{(f r)}=f_{3}\left(P_{\mathrm{d} y n} / H_{d y n}\right) ; \quad U_{\phi}^{(f r)}=f_{4}\left(P_{\mathrm{d} y n} / H_{d y n}\right) .
\end{aligned}
$$

(Index $\left(f_{r}\right)$ in the formulas means that these characteristics must be determined taking into account the resistance of friction on the sole of the rail and the resistance of the rail fasteners).

These researches were performed on the South-Western Railway (Ukrainian Railways) on the example of tests of various constructions of the railway track on reinforced concrete and wooden sleepers with modern designs of domestic fasteners unlined and lined types (KB, KPP-5, KPP-1, D0).

Thus, to solve the problem in full formulation (with the definition of exact values of deformations and stresses in the rail thread) it is necessary first of all to determine with sufficient accuracy the specified characteristics of the spatial elasticity of rail threads under joint action of vertical and horizontal dynamic forces $P_{d y n}$ and $H_{d y n}$ and torque $M_{t o r}^{e x}$ from the off-center application of external forces. And only after that it is possible to pass to definition of the required spatial deformations of rail threads and stresses in this rail threads.

Theoretical bases of calculations of a rail on horizontal bending and torsion was developed by distinguished Ukrainian scientist professor S. P. Tymoshenko ${ }^{1}$ at the beginning 20 century (1926-1932) [8,9].

Taking the rail as a beam of infinite length, which rests and is attached to an elastic base, and considering horizontal bending of the rail in conjunction with simultaneous torsion under action of horizontal force $\mathrm{H}$, that eccentrically applied to the head of the rail (Figure 1) prof. Tymoshenko composed the system from two differential equations for calculating rail horizontal strains and its torsion deformations as follows:

$$
\left.\begin{array}{c}
E I_{z} \frac{d^{4} y}{d x^{4}}=-U_{y}\left(y_{0}-h_{2} \cdot \phi\right) \\
-C \frac{d^{2} \phi}{d x^{2}}+D h_{Q}^{2} \frac{d^{4} \phi}{d x^{4}}=U_{y}\left(y_{0}-h_{2} \cdot \phi\right) \cdot h_{2}-U_{\varphi} \cdot \phi=0
\end{array}\right\}
$$

In the system of equations (1), the first equation determines the lateral transverse bending of the rail from the action of the transverse horizontal force $\mathrm{H}$; the second equation determines the torsion of the rail relative to the longitudinal axis $(X-X)$ passing through the center of torsion (which for the rail coincides with the center of bending $(\cdot) 0$ ). In this case, the torsion (according to the theory of prof. Tymoshenko) consists

\footnotetext{
${ }^{1}$ Prof. S. P. Tymoshenko should be well known to scientists and mechanical engineers of the USA, as he worked for a long time in the USA (1922-1955) including: the American Society of Mechanical Engineers; the University of Michigan; Stanford University at Palo Alto. In the USA he published several scientific monographs: "Resistance of Materials", "Theory of Elasticity", "Theory of Vibrations" and others.
} 
of 2 types: «pure torsion» of the entire rail and «bending torsion» of the head and sole of the rail relative to its neck.

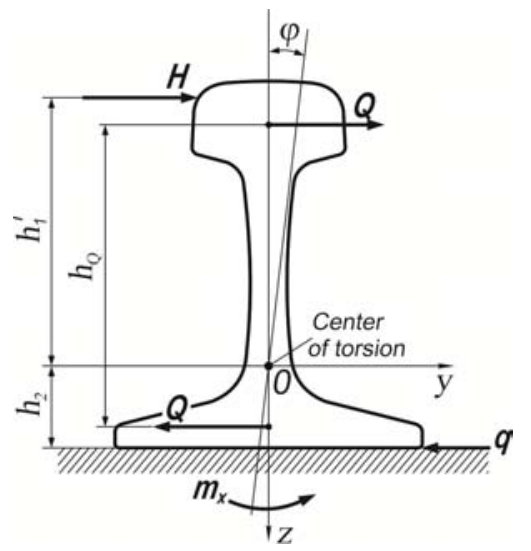

Figure 1. Calculated model of the rail thread (by prof. Tymoshenko).

In the right part of the 1-st formula equation (1) is recorded the lateral reaction of the sole of the rail «q» (relative to the one unit length of the rail) to the action of the external horizontal lateral force $H$ :

$$
\frac{d Q}{d x}=q=U_{y}\left(y_{0}-h_{2} \cdot \phi\right)
$$

In the right part of the 2-nd formula equation (1) is recorded the reaction of the one unit of rail length to the action of external torque moment $M_{t o r}^{e x}$, which consists of pure torsion $M_{l}$ and bending torsion of the head and sole of the rail relative to its neck $M_{2}$.

$$
\frac{d M_{t o r}^{e x}}{d x}=q \cdot h_{2}-m_{x}=U_{y}\left(y_{0}-h_{2} \cdot \phi\right) \cdot h_{2}-U_{\phi} \cdot \phi
$$

Here $M_{\text {tor }}^{e x}=M_{1}+M_{2}$ :

$$
M_{1}=-C \frac{d \phi}{d x}, M_{2}=D h_{Q}^{2} \frac{d^{3} \phi}{d x^{3}}
$$

In equations $(1,2,3,4)$ taken:

$y_{0}$ - horizontal transverse displacement of the center of bending of the rail (·) 0 (the same is torsion center) in the calculated cross section;

$\varphi$ - angle of turn of the calculated cross section of the rail;

$U_{y}$ - modulus of elasticity of the rail base (in the horizontal transverse plane);

$U_{\varphi}$ - modulus of elasticity of the base of the rail in torsion relative to the longitudinal axis $X$;

$q$ - lateral reaction of the sole of the rail (relative to the one unit length of the rail);

$Q$ - transverse forces that arise in the head and in the sole of the rail under action of external force $H$;

$m_{x}$ - reactive torque moment, attributed to the one unit length of the rail;

$h_{2}$ - distance from the rail center of torsion to the bottom of the rail sole;

$h_{Q}$ - distance between the centers of gravity of the head and the sole of the rail (in the calculations can usually be taken $h_{Q}$ as the distance from the center of gravity of the sole to the point of application of the horizontal force $H$ );

$C=F^{4} \cdot G /\left(4 \pi^{2} \cdot I_{p}\right)$ - rigidity of a rail at «pure» torsion (according to Saint-Venant);

$D=E \cdot\left(I_{z}^{\text {head }} \cdot I_{z}^{\text {sol }}\right) /\left(I_{z}^{\text {head }}+I_{z}^{\text {sol }}\right)$ - rigidity of the rail during bending rotation of the head and sole of the rail relative to its neck (according to Tymoshenko).

In formulas for " $C$ " and " $D$ " indicated: $F$ - cross sectional area of the rail; $G$ - shift modulus of rail steel; $I_{p}$ - polar moment of inertia of the rail; $E$ - modulus of elasticity of the rail steel; $I_{z}^{\text {head }}, I_{z}^{\text {sol }}$ - moments of inertia of the head and sole of the rail relative to the axis $\mathrm{Z}$.

The theory of prof. Tymoshenko became the basis for further research in this area. A number of scientists in the future (in the twentieth century) tried to improve the theoretical solution or test the numerical results of the theory of prof. Tymoshenko $[10,11,12]$, but as a rule, no significant successful results were achieved.

However, the main disadvantage of the decision of prof. Tymoshenko was not taking into account the action of vertical forces $P$ on the rail and the resulting friction forces on the sole between the rail and the subrail base, as well as the lack of consideration of the attachment of the rail to the elastic base, which gives a significant discrepancy with the real picture of wheel and rail operation.

It should be noted that the most successful and effective task of improving the solution of prof. Tymoshenko managed to perform one of the leading professors of VNIIZT (Russia) prof. Yershkov, who in 1950-60 considered and performed in detail a study $[13,14]$ on the calculations of the rail thread for transverse bending and torsion in a more complex (than prof. Tymoshenko) version: under the joint action on the rail vertical and horizontal forces $P$ and $H$, taking into account the emerging on the sole of the rail friction forces. The rail was considered as a beam on an elastic base.

However, the researches of prof. Yershkov were made on outdated (for now) structures (the main experiments were adopted rails type I-a (close analogue of R43), wooden sleepers, crutches. In addition, as shown by our modern research [6, 7, 15], some theoretical and practical results obtained in the works of prof. Yershkov, need significant corrections. Therefore, the application of research results from prof. Yershkov is currently practically impossible for modern track structures, due to a significant change of the upper structure of the track and their geometric and physical characteristics, as well as taking into account the need for certain corrections these results on the whole.

Based on the analysis of previously performed researches on the subject for our solution - the solution of the problem of calculating stresses and strains in the railway track in the full formulation, we take as a basis the theoretical solutions of professors Tymoshenko and Yershkov (despite some remarks to them) and we will consider the work of the rail thread on the spatial bending in the longitudinal vertical and transverse horizontal planes and also on its simultaneous torsion relative to the longitudinal axis $\langle X\rangle$ - from the joint action on the rail 
vertical and horizontal forces $P$ and $H$ and torque moment $M_{\text {tor }}$.

\section{Elaboration of Basic Calculation Schemes and Calculation Algorithm for Solving the Problem}

Given the complexity of the problem, the general calculation scheme includes two separate schemes:

1. (Figure 2-a) is a diagram of the propagation of the wave of elastic deflections of the rail thread in the vertical longitudinal plane $X O Z$ and in the horizontal longitudinal plane $X O Y$ with joint action on the rail thread of vertical force $P$ and horizontal force $H$. For the 1-st stage to simplify the obtaining of analytical formulas, the forces $P$ and $H$ are taken as concentrated forces applied in the calculated cross section $Z O Y$;

2. (Figure 2-b) - the scheme of action of external forces and moments on the elementary section of the rail thread, in the calculated cross section in the plane $Z O Y$ and the emerging reactive components of the resistance of the rail thread to external forces and moments.

In general, the calculation scheme is accepted approximately similar to the scheme of prof. Yershkov [13, 14], in which he considered the problem of calculating the rail thread on the joint action of the vertical force $\mathrm{P}$ and the lateral horizontal force $\mathrm{H}$. But we made significant corrections in the basic calculation scheme in accordance with the classical theory of work under load of beams on an elastic basis. Accordingly, changes have been made in the integration of the plots of vertical $\left(z_{i}=f(x)\right)$ and horizontal deflections $\left(y_{i}=f(x)\right)$ in solving the problem. Also in addition we put in to the calculation scheme a diagram of the distribution along the length of the angles of rotation $\left(\varphi_{i}=f(x)\right)$ of the rail in the plane $Z O Y$ relative to the vertical axis $Z$.

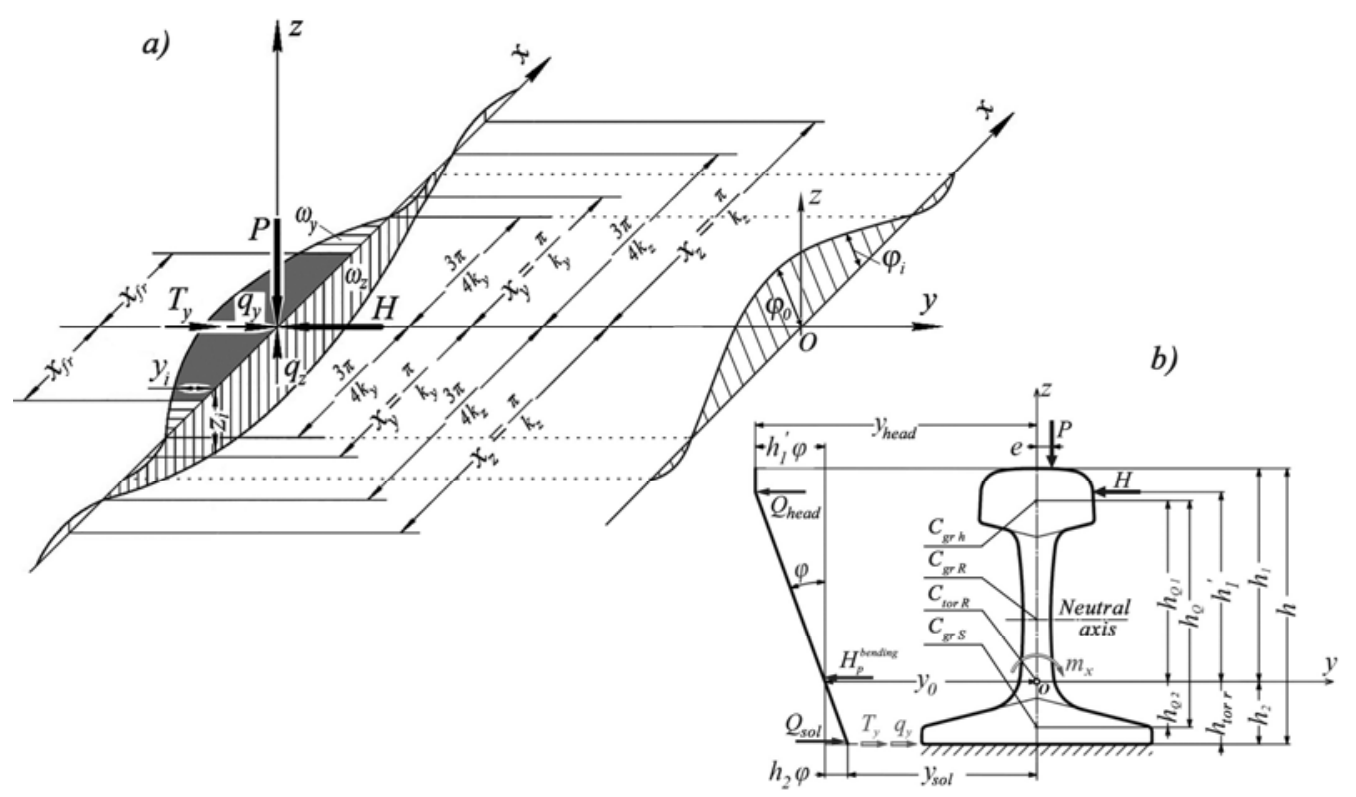

Figure 2. Basic calculated model for determining the characteristics of spatial stiffness and elasticity of the rail threads (by prof. O. Yershkov and prof. E. Danilenko). In figure. b) denotes: $C_{\text {tor } R}-$ Center of torsion (for rail); $C_{g r}-$ center of gravity (for rail); $C_{g r}-$ senter of gravity (for head of rail); $C_{g r}-$ center of gravity (for sole of rail).

The accepted basic calculation scheme is universal in the sense that allows to consider work of a rail thread (in settlement section) under interaction of the set of external loadings (vertical force $\mathrm{P}$, horizontal transverse force $\mathrm{H}$, the moment of torsion), at simultaneous consideration and taking into account working conditions of the same rail threads, as beams of infinite length fixed on an elastic basis in longitudinal vertical and longitudinal horizontal planes and taking into account resistance of rail fastenings depending on its designs.

The moment of torsion from external forces according to calculation scheme is determined by the formula:

$$
M_{\text {tor }}^{e x}=H \cdot h_{1}^{\prime} \pm P \cdot e
$$

The sign \pm before $P \cdot e$ is accepted depending on the sign \pm before eccentricity «e».

The main calculation equations for solving the problem of determining the desired values of deformations and stresses of the rail thread with its lateral transverse bending and torsion relative to the longitudinal axis $\mathrm{X}$ are the equations of prof. Tymoshenko (1-a) and (1-b), as well as equations $(2,3)$ and $(10,11)$. However, to determine the desired values of the lateral displacements of the rail thread $\left(y_{i}\right)$ and the desired angles of rotation $\left(\varphi_{i}\right)$ must first determine the unknown characteristics of the elasticity of the rail thread in the transverse horizontal plane $\left(U_{y}\right)$ and torsion $\left(U_{\varphi}\right)$ and, as well as characteristics stiffness of the rail thread $\left\langle E I_{z}\right\rangle,\langle\mathrm{C} »,\langle\mathrm{D} »$ and corresponding geometric cross - sectional characteristics of the rail $h_{2}, h_{Q}$. Geometric characteristics $E I_{z}, h_{2}, h_{Q}$ - are determined from reference data. Other unknown characteristics - modulus of elasticity $\left(U_{y}, U_{\varphi}\right)$ - are determined in the process of solving the problem, and above all from the consideration of the equations of equilibrium of 
the rail thread for the accepted calculation scheme ${ }^{2}$.

It should be noted, that in solving this problem the effect of the vertical force $\mathrm{P}$ is considered only as a factor that directly affects to the formation of the characteristics of the stiffens and elasticity of the rail thread during its lateral horizontal bending and torsion.

Equilibrium equations for rail thread are based on the general principle of resistance of materials: the equality of external forces acting on the structure that is considered, the forces of reactive resistance that occur in the structure.

For the accepted calculation scheme, the equations of equilibrium of the rail thread will be as follows:

- in the vertical longitudinal plane ZOX:

$$
\Sigma q_{z}=P
$$

or in integral form:

$$
\int_{-x_{z}}^{+x_{z}} U_{z} \cdot z \cdot d x=P
$$

- in the horizontal transverse plane YOZ:

$$
\Sigma q_{y}+\Sigma T_{y}=H
$$

or in integral form:

$$
\int_{-x_{y}}^{+x_{y}} \mathrm{U}_{\mathrm{y} 0}\left(\mathrm{y}_{0}-\phi \mathrm{h}_{2}\right) d x+\int_{-x_{y}}^{+x_{y}} \mathrm{U}_{z} \cdot z \cdot f \cdot d x=H
$$

- when torsion the rail relative to the longitudinal axis $\mathrm{X}$ :

$$
\Sigma m_{x}-\Sigma q_{y} \cdot h_{2}-\Sigma T_{y} \cdot h_{2}=M_{t o r}^{e x}
$$

or in integral form:

$$
\begin{gathered}
\int_{-x_{\phi}}^{+x_{\phi}} \mathrm{U}_{\phi} \cdot \phi \cdot d x-h_{2}\left[\int_{-x_{y}}^{+x_{y}} \mathrm{U}_{y}\left(y-\phi \cdot h_{2}\right) d x+\right. \\
\left.\quad+\int_{-x_{T}}^{+x_{T}} \mathrm{U}_{z} \cdot z \cdot f \cdot d x\right]=H \cdot h_{1}^{\prime}-P \cdot e
\end{gathered}
$$

After replacing the expression in square brackets in the formula (11) by the horizontal lateral force $H$ (according to the formula (9)), the equation of equilibrium of the rail thread during torsion will have a simpler form:

$$
\int_{-x_{\phi}}^{+x_{\phi}} U_{\phi} \cdot \phi \cdot d x-h_{2} \cdot H=H \cdot h_{1}^{\prime}-P \cdot e
$$

\footnotetext{
${ }^{2}$ New method of calculating the stress state of the rail thread under combined action on the rail of $\mathrm{P}_{\mathrm{dyn}}$ and $\mathrm{H}_{\mathrm{dyn}}$ and $\mathrm{M}_{\text {tor }}$ can be named after the authors of its development professors O. Yershkov and E. Danilenko.
}

The right-hand side of equation (12) is the torque moment of external forces:

$M_{\text {tor }}^{e x}=H \cdot h_{1}^{\prime}-P \cdot e(5)$ and characteristics $h_{1}^{\prime} ; e$ - are the eccentricities of the application of external forces $H$ and $P$ relative to the center of torsion of the rail ( $) 0$ (see Figure 2-b).

Further, taking into account that the problem of calculating deformations and stresses in the vertical plane has already been solved in the «Rules for calculating the railway track for strength» [4] we simplify our problem and solve only the equation of equilibrium of the rail in the horizontal the transverse plane $X O Y$ and the equation of equilibrium of the rail thread during its torsion relative to the longitudinal axis $X$, but in both cases we take into account the influence of the vertical force $P$ on the desired deformation of the transverse bend and torsion of the rail thread.

\subsection{At the First Stage We Consider the Problem of Transverse Lateral Bending of a Rail Thread at Joint Action on a Rail of Vertical and Horizontal Forces}

The calculation scheme for solving the problem of lateral bending of the rail thread taking into account the forces of friction on the sole of the rail, with the joint action on the rail of the vertical force $\langle P »$ and the horizontal force $\langle H\rangle$ is taken in Figure 2.

Resistance reactions $q_{y}$ and $T_{y}$ on the sole of the rail in the calculated cross section (Figure 2-b) (attributed to the unit length of the rail), taking into account the friction forces on the sole of the rail, according to research prof. Yershkov $[13,14]$ are determined by the formulas (13):

$$
\left.\begin{array}{c}
\mathrm{q}_{\mathrm{y}}=U_{y} \cdot\left(y_{0}-\varphi \cdot h_{2}\right) \\
\mathrm{T}_{\mathrm{y}}=U_{z} \cdot z \cdot f
\end{array}\right\}
$$

where $U_{y}$ - is the modulus of elasticity of the subrail base at the horizontal transverse bending of the rail thread from the action of only the lateral horizontal force (excluding the action of vertical forces and friction forces on the sole of the rail);

$y_{0}-$ is the horizontal lateral deflection of the rail in the cross section of the applied force $H$ (here the displacement of the center of the lateral bending of the rail is taken);

$U_{z}$ - is the modulus of elasticity of the subrail base with vertical bending of the rail thread;

$z-$ is the vertical deflection of the rail in the cross section of the application of force;

$f$ - is the coefficient of friction on the sole of the rail.

Turning further to the consideration of the rail thread as a long beam on an elastic basis, it is necessary to consider the calculation scheme in Figure 2-a), which shows the spatial bending of the rail thread under the combined action of vertical $P$ and horizontal (lateral) load $H$.

It is obvious that when the rail thread is laterally bent along the entire length of the rail sole, there will be continuously distributed reactive forces $q_{y}$ from the base resistance, as well as reactive components of friction forces $T_{y}$ along the rail sole (as a result of acting vertical forces during horizontal movement of the rail sole). 
The sum of all reactions of resistance on the sole of the rail in the horizontal transverse plane according to formula (8) is equal to the external lateral force $H$.

To solve the problem mathematically and for generalization the action of all forces along the length of the transverse (lateral) deformation of the rail we need to express equation (8), in integral form (9).

And then it is necessary to solve equation (9) with respect to the desired value of the modulus of elasticity $\left(U_{y}\right)$ of the rail thread in the transverse (lateral) plane.

Here $\pm x_{y}$ are the limits of integration at horizontal lateral bending.

As calculations show, the desired modulus of elasticity $U_{y}$, in the transverse bending of the rail thread, which must be determined in this problem, is not equal to the initial modulus $\mathrm{U}_{\mathrm{y}} \neq \mathrm{U}_{y}^{0}$, which is initially accepted under the action of only lateral force $H \neq 0$ and in the absence of vertical force $P(P=0)$. The initial modulus of lateral elasticity $\left(\mathrm{U}_{y}^{0}\right)$ is known because it is determined in advance in experimental studies of the stiffness of the rail threads in different designs of the track (usually at $P=0$ ).

Equation (9) is the starting point for solving the problem of lateral bending of the rail thread from the joint action of lateral and vertical forces and taking into account the forces of friction on the sole of the rail and the resistance of the rail fasteners. But to solve equation (9) in the form we need, we must to consider this equation in more detail and make some necessary transformations. Consider these transformations.

From the theory of calculation of beams on an elastic basis $[4,15]$ and according to figure $2-a$ can be seen that to ensure sufficient accuracy of calculations, the first integral of the equation (9) can be taken within limits: $-x_{y}=-\pi / k_{y}$ to $+x_{y}=$ $+\pi / k_{y}$.

The second integral cannot be taken within the same limits [13], as it exists only when moving the sole of the rail on the base, which is possible only if the friction forces on the sole of the rail are less than the elastic forces of resistance to movement on the sole, ie in the presence of inequality:

$$
U_{y}\left(y_{0}-\phi \cdot h_{2}\right)>U_{z} \cdot z \cdot f
$$

Under conditions of stable equilibrium of the rail, ie with the equality of the forces of elastic resistance of the base to the forces of friction on the sole of the rail, inequality (14) takes the form of the equation:

$$
U_{y}\left(y_{0}-\phi \cdot h_{2}\right)=U_{z} \cdot z \cdot f
$$

In equation (15) in addition to the desired value $U_{y}$ - the horizontal lateral modulus of elasticity of the rail thread, the following are unknown: $y_{0}$ - horizontal transverse displacement of the center of bending of the rail from the force $H$, and $\varphi$ - the angle of torsion of the rail section. The following values are considered know in advance: $z-$ is the vertical displacement of the rail thread under the influence of force $P$ and also $U_{z}$ - is the modulus of elasticity of the rail thread during vertical bending (these values are known from the solution of the problem of vertical bending of a rail thread lying on a solid evenly elastic base) [4]).

According to the accepted calculation scheme (figure 2-b) it is possible to write down formulas for definition of size of horizontal transverse displacements of a head and a rail sole in settlement cross-section where forces $H$ and $P$ are applied:

$$
\begin{gathered}
y_{\text {sol }}=y_{0}-\phi \cdot h_{2} \\
y_{\text {head }}=y_{0}+\phi \cdot h_{1}^{\prime}
\end{gathered}
$$

Many studies have shown that the stiffness of the rail thread on the sole is significantly greater than the stiffness on the head, ie in general can be written:

$$
y_{\text {sol }}=\frac{y_{\text {head }}}{\delta}
$$

The coefficient $« \delta »$ depends on the type of rails, type of fasteners and underrail supports. In the works of prof. Yershkov $[12,13]$ for rails of types R43, I-a and R50, which are embedded on wooden sleepers, it was assumed $\delta=2.0$.

In our researches in 2012-2016 [5, 7, 15] it is established that for modern types of fasteners of Ukrainian railways the value of the coefficient $\delta$ can vary widely from $\delta=2,0$ to $\delta=$ 4,0 when using different types of rails, fasteners and underrail supports. Therefore, for further considerations, it is advisable to take the value of the ratio in general:

$$
\delta=\frac{y_{\text {head }}}{y_{\text {sol }}}
$$

Using formulas (16), (17) and (19) we can make a relationship between the values of the horizontal transverse deformations of the head and sole of the rail thread:

$$
y_{0}-\phi \cdot h_{2}=\frac{y_{0}+\phi \cdot h_{1}^{\prime}}{\delta}
$$

From the formula (20) after simple transformations, we can obtain a formula for determining the angle of turn of the rail section $\varphi$ as a function of the transverse lateral displacement of the center of bending of the rail thread $y_{0}$ :

$$
\phi=\frac{y_{0} \cdot(\delta-1)}{h_{1}^{\prime}+\delta \cdot h_{2}}
$$

For further solutions, we also need to find the ratio between the values of the horizontal transverse deflection $y_{0}$ of the rail thread along the line of the centers of bending along the $X-X$ axis and the transverse deflections along the sole of the rail thread. We can obtain that equation after transformation the formula (16) by inclusion in it formula (21) for calculating the angle $\varphi$ and solving this equation with respect to the deflection of the sole $y_{\text {sol }}$. As a result we will receive: 


$$
y_{s o l}=\left(y_{0}-\phi \cdot h_{2}\right)=\frac{\left(h_{1}^{\prime}+h_{2}\right)}{h_{1}^{\prime}+\delta \cdot h_{2}} \cdot y_{0},
$$

For a further solution, we use the next most important (after equation (9)) equation (15), which determines the condition of stable equilibrium of the elastic resistance of the base and the friction forces on the sole of the rail.

To do this, convert the original equation (15) to the following form:

$$
\frac{U_{y}\left(y_{0}-\phi \cdot h_{2}\right)}{U_{z} \cdot f}=z_{0},
$$

And then after substitution in the formula (23) instead of the expression $\left(y_{0}-\varphi \cdot h_{2}\right)$ equal to it the right part of the formula (22), and performing some transformations, you can get a very important formula for the ratio of vertical and horizontal deformations of the rail thread at point 0 , which is both center of torsion and bending of the cross section of the rail under the action of forces $H$ and $P$ :

$$
\frac{z_{0}}{y_{0}}=\frac{\left(h_{1}^{\prime}+h_{2}\right)}{\left(h_{1}^{\prime}+\delta \cdot h_{2}\right)} \cdot \frac{U_{y}}{U_{z} \cdot f}
$$

Formula (24) is very important because it establishes the relationship between the vertical and horizontal deflections of the rail $z_{0} / y_{0}$ in the calculated cross section under the joint action of forces $H$ and $P$ (Figure 2-b) for conditions of stable equilibrium of the rail (ie with equal elastic resistance of the base to friction forces on the sole of the rail). This formula allows you to determine the magnitude of the horizontal deflections of the rail thread in the center of the bend ( $\left.y_{0}\right)$, as well as deflections along the sole $\left(y_{\text {sol }}\right)$ and the head ( $\left.y_{\text {head }}\right)$ after some transformations.

For further considerations, we note that the vertical deflection of the line of the centers of bending of the rail is the same for the entire cross section of the rail, ie it is also equal to the vertical deflection of the sole of the rail $z_{0}=z_{\text {sol }}$.

Using the well-known from the theory of calculation of beams on an elastic basis the relationship (25) between the magnitude of the deflections in the vertical and horizontal planes and the ordinates of the diagrams of elastic deflections distributed along the length of the rail thread (see Figure 2-a) after some transformations we can get once more very important formula (26) by next way.

From the theory of calculation of beams on an elastic basis $[4,15,16]$ it is known that the required vertical and horizontal displacements in the calculated sections are determined by the following expressions:

$$
\left.\begin{array}{rl}
z_{i} & =\frac{P \cdot k_{z}}{2 \cdot U_{z}} \cdot \eta_{z i} \\
y_{i} & =\frac{H \cdot k_{y}}{2 \cdot U_{y}} \cdot \eta_{y i}
\end{array}\right\}
$$

where $\eta_{z i}, \eta_{y i}-$ are the ordinates of the diagrams of elastic deflections distributed along the length of the «X $\mathrm{x}$ » rail, respectively, in the vertical and horizontal planes. These ordinates are determined depending on the argument $\left(k_{z} \cdot x_{i}\right)$ or $\left(k_{y} \cdot x_{i}\right)$ and show a picture of the distribution of deflections (vertical and horizontal, respectively) along the length of the rail for the case of joint application of vertical and horizontal forces $P$ and $H$ in one calculated section (see Figure 2-a).

In addition to the previously accepted notation in formulas (25) marked:

$k_{z}, k_{y}$ - coefficients of relative rigidity between the elastic base and the rail, respectively: $\left.k_{z}=\sqrt[4]{U_{z} /\left(4 E I_{y}\right.}\right)-$ with vertical bending of the rail thread; $k_{y}=\sqrt[4]{U_{y} / 4 E I_{z}}$ - at horizontal bending of a rail thread. Coefficients $k_{y}$ and $k_{z}$ determined from the theory of calculation of beams on elastic basis $[4,15,16]$.

After substituting expressions (25) in equation (24), performing the appropriate transformations, we obtain the required formula (26) to determine the ordinates of the plot of horizontal transverse deflections $\left(\eta_{y 0}\right)_{i}$ (see Figure 2-a).

This ratio is truthful for the line of deflection centers of the rail thread along its entire length.

$$
\left(\eta_{y 0}\right)=\frac{\left(\eta_{z 0}\right)_{i} \cdot\left(h_{1}^{\prime}+\delta \cdot h_{2}\right) \cdot k_{z} \cdot P \cdot f}{\left(h_{1}^{\prime}+h_{2}\right) \cdot k_{y 0} \cdot H}
$$

Formula (26) is the desired formula for determining the ordinates of the plot of horizontal transverse deflections $\left(\eta_{y 0}\right)_{i}$ (along the axis of the centers of bending of the rail) in any section along the length of the rail thread as a function of several given parameters known from the condition of the problem, namely: from the ordinates of known vertical deflections $\left(\eta_{z}\right)_{i}$; as a function of the ratio of acting forces $(P / H)$, and also as a function of the coefficients of relative stiffness of the rail thread $k_{z} / k_{y 0}$ (when bending the rail thread in vertical and transverse horizontal planes):

In formula (26) the values $\eta_{z 0}$ and $k_{z}$ are considered to be given from the solution of the problem of vertical bending of the rail thread for the rail as a beam on an elastic basis.

The coefficient of relative stiffness of the base of the rail thread and rail $\left(k_{y 0}\right)$ when exposed to the rail only the lateral force $H$ and in the absence of force $P(P=0)$, is determined by solving the differential equation:

$$
E I_{z} \frac{d^{4} y_{0}}{d x^{4}}+U_{y} \cdot y_{0}=0,
$$

The solution of this equation $[15,16]$ for determining the horizontal transverse deflections of the rail thread $\left(y_{0}\right)$ (for the line of the centers of bending), within the entire length from $x_{\min }$ to $x_{\max }$ has the form:

$$
y_{0}=\frac{H \cdot k_{y 0}}{2 \cdot U_{y}} \cdot e^{-k_{y 0} \cdot x} \cdot\left(\cos k_{y 0} \cdot x+\sin k_{y 0} \cdot x\right)
$$

After substitution in equation (28) value $U_{y}$ in the form of a known ratio $U_{y}$ and $k_{y}$ : 


$$
U_{y}=\left(k_{y 0}\right)^{4} \cdot 4 E I_{z}
$$

and taking in the expression (28) abscissa $x=0$ (for the section at the point of application of force $H$ ) we obtain the formula (30) to determine the magnitude of the deflections for the line of the centers of bending $\left(y_{0}\right)$ and from the formula (30) we obtain the expression (31) to determine the relative stiffness coefficient $k_{y 0}$ :

$$
\begin{gathered}
y_{0}=\frac{H}{8 \cdot\left(k_{y 0}\right)^{3} \cdot E I_{z}}, \\
k_{y 0}=\sqrt[3]{\frac{H}{8 E I_{z} \cdot y_{0}}}
\end{gathered}
$$

The value of the modulus of elasticity of the subrail base is determined by the formula (29).

To be able to apply formula (24) to solve the problem of determining the horizontal deflections of the rail thread on the plane of the sole depending on the vertical deflections of the rail, with joint action on the rail thread forces $P$ and $H$, consider the existing relationship between transverse deflections of rail thread on the sole and on the line of bending centers of the rail $X-X$.

For this solution it is sufficient to use the previously given relations between $y_{s o l}$ and $y_{0}$ (see formula (22)).

From which it follows that in order to move from the transverse deflections along the line of the centers of bending $\left(y_{0}\right)$ to the transverse deflections along the sole of the rail $\left(y_{s o l}\right)$, it is necessary to multiply the value $\left(y_{0}\right)$ by a factor $\left(h_{1}^{\prime}+h_{2}\right) /\left(h_{1}^{\prime}+\delta \cdot h_{2}\right)$. This conclusion also applies to the ordinates $\left(\eta_{0}\right)$ of the plot of deflections $\left(\eta_{0}\right)$.

Thus, we obtain the final required formula for determining the ordinates of the diagram of the transverse horizontal deflections of the rail thread on the sole $\left(\eta_{y \text { sol }}\right)$ (taking into account the friction forces) in any cross section along the length $X$-X under combined action on the rail vertical and horizontal forces: $H \neq 0$ and $P \neq 0$ :

$$
\left(\eta_{y s o l}\right)_{i}=\frac{\eta_{z i} \cdot k_{z} \cdot P \cdot f}{k_{y 0} \cdot H}
$$

At the next stage of solving the problem it is necessary to determine the modulus of elasticity of the subrail base at the transverse horizontal bending of the rail thread $\left(U_{y}^{(f r)}\right)$ from the joint action of horizontal and vertical forces: $H \neq 0 ; P \neq 0$ (taking into account the elastic resistance of the base and the forces of friction on the sole of the rail).

To solve this problem, proceed as follows.

1) In experimental studies of the vertical bending of the rail thread under the influence of the vertical concentrated force $P$ prof. Yershkov [13] found that the vertical modulus of elasticity of the subrail base is defined as the ratio of the total force to the total value of the vertical deflections along the entire length of the deformed rail, ie:

$$
U_{z}=\frac{P}{\omega_{z}}=\frac{P}{\int_{-x_{\min }}^{+x_{\max }} z \cdot d x}
$$

When solving the problem of rail deflection as beams on an elastic basis, it is established that for practical purposes it is sufficient to take for calculations the elastic wavelength of deflections, including the entire zone of positive deflections plus two sections of the negative deflection zone (on both sides of the positive zone) up to absolutely minimum ordinate $\eta_{\min }=-0,0432$. That is, the length of the elastic wave of deflections is taken into account in the range from $\mathrm{x}_{\min }=-\pi /$ $\mathrm{k}_{\mathrm{z}}$ to $\mathrm{x}_{\max }=+\pi / \mathrm{k}_{\mathrm{z}}$ (let's call it the calculated length of the elastic wave of vertical deflections). That is, you can take the area of the plot of the ordinate vertical deflection of the rail within the integration from $-x_{\min }=-\pi / k_{z}$ to $+x_{\max }=+\pi / k_{z}$, where area of the plot is:

$$
\omega_{z}=\int_{-\frac{\pi}{k_{z}}}^{+\frac{\pi}{k_{z}}} z \cdot d x
$$

Then equation (33) can be rewritten as follows:

$$
U_{z} \int_{-x_{\min }}^{+x_{\max }} z \cdot d x=P \text { or } \int_{-\frac{\pi}{k_{z}}}^{+\frac{\pi}{k_{z}}} U_{z} \cdot z \cdot d x=P
$$

2) Consider now in more detail the equilibrium equation (9) in the horizontal plane, expressed in integral form.

Under the first integral the expression $\left(y_{0}-\varphi \cdot h_{2}\right)$ denotes the transverse displacements of the rail sole, and the whole integral without the modulus of elasticity $U_{y}$ is the area of the plot of the ordinates of the horizontal transverse deflection of the rail sole $\left(\omega_{y}\right)^{\text {sol }}$, which for practical purposes, similarly to vertical deflections, is also accepted within $x_{\min }=-\pi / k_{y} ; x_{\max }=+\pi / k_{y}$ :

$$
\int_{-\frac{\pi}{k_{y}}}^{+\frac{\pi}{k_{y}}}\left(y-\phi \cdot h_{2}\right) \cdot d x=\omega_{y}^{s o l}
$$

That is, the entire first integral of equation (9) can be rewritten as:

$$
\int_{-x_{y}}^{+x_{y}} U_{y}\left(y-\phi \cdot h_{2}\right) \cdot d x=U_{y} \cdot \omega_{y}^{s o l}
$$

Now substitute expression (37) in equation (9) and rewrite equation (9) relative to the horizontal (transverse) modulus of elasticity of the rail thread $\left(U_{y}\right)$, then we obtain the formula (38), in which $\left(U_{y}\right)$ is expressed as a function not only of the factors that characterize deformation in the transverse plane of 
the rail thread $\left(H / \omega_{y}^{s o l}\right)$, but also it take into account the influence of vertical bending and friction forces on the sole of the rail (which is characterized by the second integral of the expression (9)):

$$
U_{y}=\frac{H-\int_{-x_{y}}^{+x_{y}} U_{z} \cdot z \cdot f \cdot d x}{\omega_{y}^{\text {sol }}}
$$

In formula (38) the second term in the numerator- is the second integral of equation (9) $\left(\int_{-x_{y}}^{+x_{y}} U_{z} \cdot z \cdot f \cdot d x\right)$,

which denotes the sum of friction forces on the sole of the rail and which can exist only within the elastic wavelength of the horizontal bend of the rail, ie within from $-x_{y}=-x_{f r}$ up to $+x_{y}=+x_{f r}$, so we can write that $x_{y}$ varies within:

$$
+x_{f r} \geq x_{y} \geq-x_{f r},
$$

where $x_{f r}$ - is the half-wavelength of the friction section on the sole of the rail under the combined action of the horizontal force $H$ and the vertical force $P$. That is, the formula (38) can be rewritten as follows:

$$
U_{y}=\frac{H-\int_{-x_{f r}}^{+x_{f r}} U_{z} \cdot z \cdot f \cdot d x}{\omega_{y}^{\text {sol }}}
$$

The value $x_{f r}$ cannot be greater than the length of the active (positive) half-wave zone of the horizontal transverse bending of the rail, ie, $x_{f r} \leq 3 \pi / 4 k_{y}$ as the friction on the sole of the rail from the action of vertical force $P$ is realized only on the active part of the horizontal bending of the rail (look Figure 2-a).

Because from equation (35) it follows that when integrating within the full length of the elastic wave of vertical deflections (within the calculated area $+\pi / k_{z} \geq x_{z} \geq-\pi / k_{z}$ ) there is an equality that expressed the second integral of formula (35), then for the area $\left(+x_{f r} \geq x_{y} \geq-x_{f r}\right)$, where the friction is realized on the sole of the rail with the combined action of horizontal and vertical forces $H$ and $P$, we can write:

$$
\int_{-x_{f r}}^{+x_{f r}} U_{z} \cdot z \cdot d x=a \cdot P
$$

And then the formula (40) can be rewritten as:

$$
U_{y}=\frac{H-f \cdot a \cdot P}{\omega_{y}^{s o l}}
$$

Here $« a »-$ is the coefficient that determines the ratio of areas: plots of horizontal deflections of the rail thread within the length of the friction section (from $+x_{f r}$ to $-x_{f r}$ ) to the area of the plot of horizontal deflections at the full length of the elastic wave (from $+\pi / k_{z}$ to $-\pi / k_{z}$ ), ie «a» is the coefficient showing the share of action vertical force $P$ in the formation of the area of the friction plot, ie in the formation of resistance forces to transverse movement of the rail along its sole under the joint action of the horizontal transverse force $H$ and the vertical force $P$.

The value of the coefficient $" a$ » is determined from the ratio of formulas (41) and (35):

$$
a=\frac{U_{z} \int_{-x_{f r}}^{+x_{f r}} z \cdot d x}{U_{z} \int_{-\frac{\pi}{k_{z}}}^{+\frac{\pi}{k_{z}}} z \cdot d x}
$$

After integration, we obtain the final expression to determine the coefficient «a» in the form:

$$
a=\frac{e^{-k_{z} \cdot x_{f r}} \cdot \cos k_{z} \cdot x_{f r}-1}{e^{-\pi} \cdot \cos \pi-1}
$$

From the formula (44) it can be seen that the values of the coefficient « $a$ » vary depending on $x_{f r}$ - the length of the elastic half-wave of the friction section along the sole of the rail at horizontal bending from the joint action of forces $H$ and $P$; as it will be shown below, the length of the section $x_{f r}$ in turn depends on the ratio of vertical and horizontal forces $x_{f r}=f(P /$ $H)$. And in addition, the values of the coefficient «a» vary depending on $k_{z}$ - the coefficient of relative stiffness of the base and rail in the vertical plane.

The result of solving the problem (that proposed here) is very significantly different from the solution of prof. Yershkov $[13,14]$, where he accepted constant value of the coefficient a $=$ const $=0,9$.

In opposite to the accepted prof. Yershkov value of the coefficient $\mathrm{a}=\mathrm{const}=0,9$, in our modern research 2012-2016. $[6,7,15]$ was found that the value of the coefficient "a» is not to be constant, but on the contrary varies significantly depending on: the design of the subrail base, rail fasteners, and above all, depending on the ratio of vertical and horizontal forces $(P / H)$ and length $\mathrm{x}_{\mathrm{fr}}$ - elastic half-wave of friction on the sole of the rail at horizontal bending of the rail under conditions of joint action of forces $P$ and $H$, ie $a=f\left(k_{z}\right.$, $\left.\mathrm{P} / \mathrm{H}, \mathrm{x}_{\mathrm{fr}}\right)$.

The graph of the dependence of «a» and $x_{f r}$ as a function of $(P / H)$ has the form shown in Figure 3, where for example we give two graphs: $a=f(P / H)$ and $x_{f r}=f(P / H)$ for next designs of railway track: a) rails - R65; sleepers - reinforced concrete, a diagram of sleepers is 1840 sleep $/ \mathrm{km}$; fastners are $\mathrm{KB}$; b) rails - R50; sleepers - wooden, diagram of sleepers is 1840 sleep $/ \mathrm{km}$, fasteners are D0. 


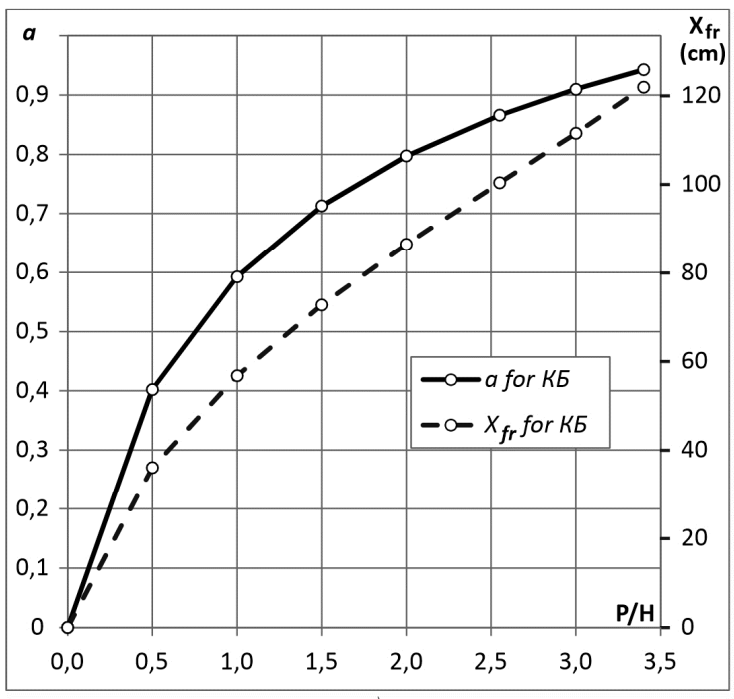

a)

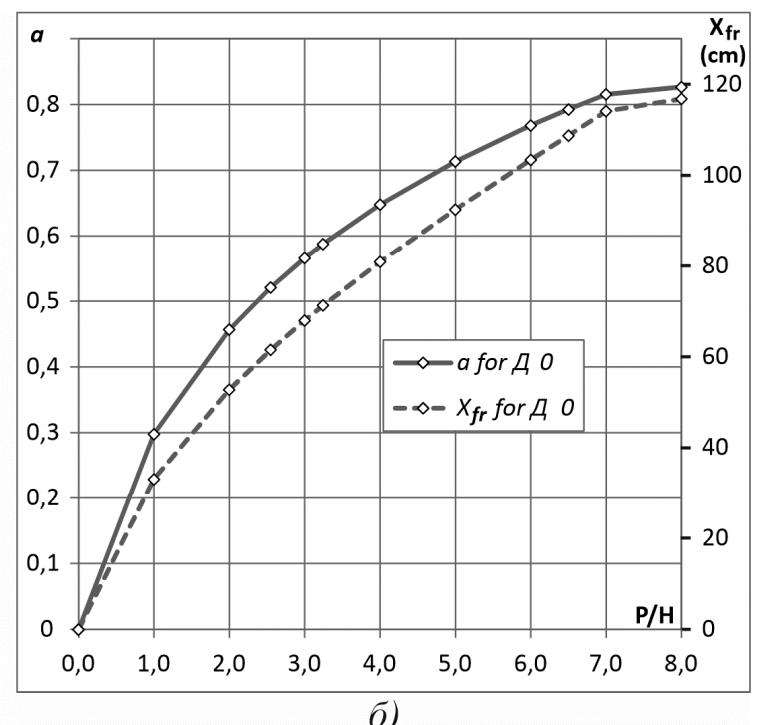

б)

Figure 3. Graph of the dependence of «a» and $x_{f r}$ as a function of $P / H:$ a) for rails $R 65$ on reinforces concrete sleepers; b) for rails R50 on wooden sleepers.

The graphical dependences $a=f(P / H)$ and $x_{f r}=f(P / H)$ for other constructions of railway track have a similar form (up to Figure 3). The numerical values of «a» and $x_{f r}$ for specific $P / H$ ratios are given in the example of calculations.

For modern constructions of the upper structure of railway track, the coefficient « $a$ » can vary in the range from $a_{\min }=0$ to $a_{\max }=1,0$ and can not be $a>1,0$, as the plot of friction forces can exist only within the wavelength of the horizontal transverse bend of the rail $2 \cdot x_{f r}$ (see Figure 2-a). And when $a_{\min }$ $=0$ that corresponds $P=0$, there will be the equality take place: $U_{y}^{(f r)}=U_{y}$. The result obtained in our research fully corresponds to the mathematical logic of the physical characteristics accepted for consideration. (On the contrary, in the existing interpretation of the solution of prof. Yershkov $[13,14]$, when $P=0$ and $a \neq 0$ formulas (48) and (50), which given below, do not correspond to mathematical logic).

The half-wavelengths of friction on the sole of the rail $x_{f r}$, for example for R65 rails with $\mathrm{KB}$ fasteners on reinforced concrete sleepers can vary from $x_{f r}^{\min }=0$ (when $P_{\min }=0$ ) up to $x_{f r}^{\max }=100 \div 125 \mathrm{~cm}$ (when $P_{\max } / H_{\max }=2,6 \div 3,5$ ) for different structures of the upper track with different fasteners. (It will be recalled that in the decisions of prof. Yershkov it was recommended to take $x_{f r}^{\max }=120 \mathrm{~cm}$ for all cases for the construction of the upper structure of the track on wooden sleepers with rails type R43 and R50).

In addition, the coefficient of friction on the sole of the rail prof. Yershkov assumed as constant $f=0,15$ for D0 type fasteners on wooden sleepers. In fact, the coefficient $f$ should be taken differently for different fasteners and for different sleepers. According to our researches, the coefficient of friction on the sole of the rail $f$ should be taken differently depending on the types of rail fasteners and rail supports. Namely, for the fasteners listed in table 1 should be taken $f$ respectively equal to: $\mathrm{KB}-0,3$; KPP-5 $-0,32$; KPP- $1-0,28$; D0 $-0,15$.

As will be shown below, the coefficient «a» has a significant effect on the determination of the modulus of elasticity $U_{y}^{(f r)}$ for the rail thread in the horizontal transverse plane.

3) After solving the problem of determining the coefficient «a» and half-wave length of friction $x_{f r}$ for different designs of upper structure of railway track, we can proceed to finding one of the most important characteristics of the rail thread - the actual (real) modulus of transverse elasticity of the subrail base for rail thread $U_{y}^{(f r)}$ under the combined action of horizontal force $H$ and the vertical force $P$ (taking into account the friction forces on the sole of the rail and taking into account the resistance of the subrail base and fasteners).

Because of the area of the plot of the ordinates of the transverse displacements of the rail sole $\omega_{y}^{\text {sol }}$ in the experiments with the combined action of the vertical force $P$ and horizontal $H$ is always determined in the presence of friction forces on the rail sole, therefore in formula (42) the ratio $\left(H / \omega_{y}^{\text {sol }}\right)$ (by analogy with (33)) should be considered as the real modulus of elasticity of the track $U_{y}^{(f r)}$ in the horizontal transverse plane in the presence of a vertical force $P$ and taking into account the friction forces on the sole of the rail:

$$
\frac{H}{\omega_{y}^{s o l}}=U_{y}^{(f r)}
$$

Then further, substituting (45) in the formula (42) and transferring the desired value of the modulus of elasticity $U_{y}^{(f r)}$ to the left, we obtain a new equation in the form of a ratio between: $U_{y}$ - the modulus of elasticity of the subrail base for rail thread at horizontal bending - for the case of acting only horizontal forces $H \neq 0$ (in the absence of vertical force $P=0$ ) and the real modulus of elasticity of the subrail base $U_{y}^{(f r)}$ for the same rail thread, that exists in the real interaction of the track with the rolling stock under the joint action of vertical force $P \neq 0$ and horizontal force $H \neq O$ (ie taking into account the friction forces on the 
rail sole).

$$
U_{y}^{(f r)}=U_{y}+\frac{f \cdot a \cdot P}{\omega_{y}^{s o l}}
$$

Now, if in the formula (40) the area of the plot $\omega_{y}^{\text {sol }}$ of transverse lateral displacements along the sole of the rail is expressed through the relation (47), which follows from (45):

$$
\omega_{y}^{s o l}=\frac{H}{U_{y}^{(f r)}},
$$

and then substitute this expression into formula (46), then making the appropriate transformations, we obtain the final calculation formula (48) to determine the desired value of the actual transverse horizontal modulus of elasticity of the subrail base of the rail thread with the combined action of vertical and horizontal forces $(\mathrm{P} \neq 0 ; \mathrm{H} \neq 0)$ and taking into account the friction forces on the sole of the rail and the resistance of the subrail base with fasteners.

$$
U_{y}^{(f r)}=U_{y} \cdot \frac{H}{H-f \cdot a \cdot P}
$$

Given the fact that in the conditions of this problem it is indicated that the problem is solved for the influence of the wheels of the rolling stock on the track, we can rewrite equation (48) in another form (taking according to the condition of the problem $\left.H=H_{d y n} ; P=P_{d y n}\right)$.

$$
U_{y}^{(f r)}=U_{y} \cdot \frac{H_{d y n}}{H_{d y n}-f \cdot a \cdot P_{d y n}}
$$

Or you can rewrite the formula (48) in a slightly different form, that is known from the reference literature $[17,18]$ as a formula obtained by prof. Yershkov. To do this, multiply the numerator and denominator of the right-hand side of equation (48) by a factor $1 / P_{d y n}$, then we obtain:

$$
U_{y}^{(f r)}=U_{y} \frac{\frac{H_{d y n}}{P_{d y n}}}{\frac{H_{d y n}}{P_{d y n}}-f \cdot a} .
$$

Formulas (48), (49), (50) obtained in our studies to determine the transverse horizontal modulus of elasticity of the subrail base of the rail thread, which is attached by fasteners to the elastic base in the vertical longitudinal plane $X O Z$ and in the horizontal longitudinal and transverse planes $X O Y$ and $Z O Y$, and is subject to deformation of vertical and horizontal bending with simultaneous torsion relative to the longitudinal axis $X$ - $X$, from the joint action of external forces vertical $P$ and transverse horizontal $H$, as well as torque moment $M^{e x}$ tor from eccentric application of forces $P$ and $H$, on the first view differ little from formulas (51) and (52), which is given in prof. Yershkov studies [14, 13] and in reference literature $[17,18]$ (according to the results of prof. Yershkov):

$$
\begin{aligned}
& U_{y}^{(f r)}=\frac{\frac{H}{P}}{\frac{H}{P}-f \cdot a} \cdot U_{y} \\
& U_{y}^{(f r)}=\frac{\frac{H_{d y n}}{P_{d y n}}}{\frac{H_{d y n}}{P_{d y n}}-0,9 f} \cdot U_{y}
\end{aligned}
$$

However, this is not so. The formulas (48), (49), (50) obtained by us are qualitatively different from formulas (51) and (52).

First, the values of the modulus of elasticity of the rail thread $U_{y}$ and the coefficient of relative stiffness $k_{y 0}$ under the action of the rail only horizontal force $H$ (and the absence of vertical force $P=0$ ) are determined in another way, namely by formulas (29) and (31).

Second, the coefficient «a», which shows the ratio of the areas of the plots of the horizontal deflections of the rail thread in the presence of friction forces on the sole of the rail and in their absence, is not a constant value and it is determined by formula (44), which differs from the recommended value $a=$ 0,9 in studies prof. Yershkov. The coefficient $« a »$ can take values from the largest $a_{\max }$ (at the most unfavorable ratio of forces $P_{\max } / H_{\max }$ ) to the minimum $a_{\min }$ (in the absence of vertical force $P=0)$. At values of vertical and horizontal loading on a rail close to real forces of interaction between a wheel and a rail $P_{d y n} / H_{d y n}$, the coefficient «a» should be recommended to accept as the most probable value $a_{p r o b}$ when $x_{f r}=x_{f r}^{p r o b}$.

Thirdly, as already mentioned, it is necessary to take different values of the coefficient «a» for different types of fasteners on reinforced concrete and wooden sleepers and also it is determined as different values depending on friction coefficients $« f\rangle$.

The results of calculations of real values of the actual modules of transverse elasticity for the subrail base of rail threads $\left(U_{y}^{(f r)}\right)$, with the joint action of vertical $P_{d y n}$ and horizontal $H_{d y n}$ wheel loads on the rail are given in table 1 for different types of track construction with rails of types R65 and R50, for track on reinforced concrete sleepers with fasteners type KB, KPP-5, KPP-1, and on wooden sleepers with fasteners D0, depending on the ratio forces $P / H$ (from probable to maximum values).

Functional dependences of the real values of the modulus of elasticity as a function of the ratio of vertical and horizontal wheel loads acting on the rail thread $U_{y}^{(f r)}=f\left(P_{d y n} / H_{d y n}\right)$ are shown in Figure 4. 


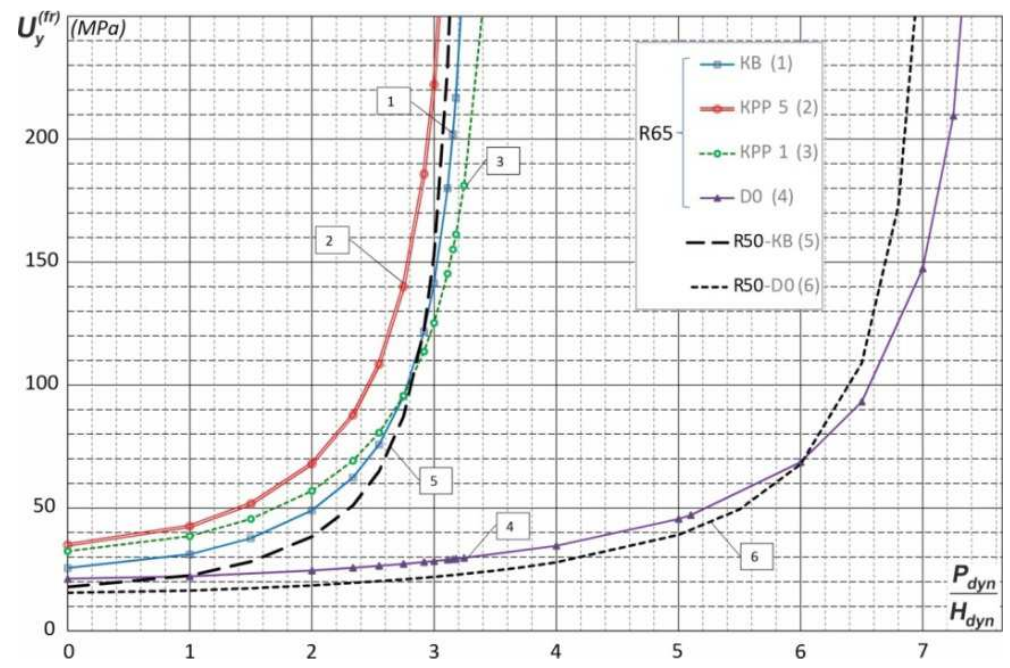

Figure 4. Graphs of functional dependences of modules of transverse elasticity on the ratio of vertical and horizontal forces $U_{y}^{(f r)}=f\left(P_{d y n} / H_{d y n}\right)$ acting on the rail thread for railway track with rails $R 65$ and R50 on reinforced concrete and wooden sleepers with different fastening structures.

Table 1. Accounted values of the real modulus of elasticity of the subrail base under horizontal transverse bending of the rail thread and under torsion for track structures with rails $R 65$ and $R 50$ on reinforced concrete and wooden sleepers with fasteners types $K B, K P P-5$, DO (given depending on P/H).

\begin{tabular}{|c|c|c|c|c|c|c|}
\hline \multirow[b]{2}{*}{$\boldsymbol{P} / \boldsymbol{H}$} & \multicolumn{2}{|l|}{ KB } & \multicolumn{2}{|l|}{ KPP-5 } & \multicolumn{2}{|l|}{ D0 } \\
\hline & $U_{y}^{(f r)}, \mathbf{k g} / \mathrm{cm}^{2}$ & $U_{\phi}^{(f r)}, \mathrm{kg} / \mathrm{rad}$ & $U_{y}^{(f r)}, \mathrm{kg} / \mathrm{cm}^{2}$ & $U_{\phi}^{(f r)}, \mathrm{kg} / \mathrm{rad}$ & $U_{y}^{(f r)}, \mathrm{kg} / \mathrm{cm}^{2}$ & $U_{\phi}^{(f r)}, \mathrm{kg} / \mathrm{rad}$ \\
\hline \multicolumn{7}{|c|}{ For rail of types $\mathrm{R} 65$} \\
\hline 0,000 & 255,81 & 52116,68 & 349,47 & 33100,93 & 211,65 & 62783,25 \\
\hline 1,000 & 311,1392 & 63389,01 & 425,2673 & 40280,26 & 221,538 & 65717,74 \\
\hline 1,500 & 376,6273 & 76731,03 & 516,9069 & 48960,13 & 231,783 & 68756,62 \\
\hline 2,336 & 623,3871 & 127003,9 & 877,9239 & 83154,77 & 256,300 & 76029,52 \\
\hline 3,000 & 1412,533 & 287778,3 & 2221,62 & 210426,4 & 283,908 & 84219,10 \\
\hline \multicolumn{7}{|c|}{ For rail of types R50 } \\
\hline 0,000 & 178,70 & 24303,67 & & & 155,51 & 29017,48 \\
\hline 1,000 & 225,50 & 30668,73 & & & 164,31 & 30659,90 \\
\hline 1,500 & 281,550 & 38285,42 & & & 173,35 & 32346,53 \\
\hline 2,336 & 510,39 & 69415,06 & & & 195,14 & 36412,08 \\
\hline 3,000 & 1530,59 & 208164,26 & & & 220,14 & 41078,09 \\
\hline
\end{tabular}

Notes. *) The ratio $\mathrm{P} / \mathrm{H}=0$ corresponds to the value of the real modulus $U_{y}$ at $\mathrm{P}=0$;

**) The ratio $\mathrm{P} / \mathrm{H} \approx 2,336$ - corresponds to the interaction of rolling stock and track for a freight 4-axle car on trolleys $\mathrm{CNII-H} 3-0$ when moving at a speed of $\mathrm{V}=$ $80 \mathrm{~km} / \mathrm{h}$ in the curve $\mathrm{R}=900-800 \mathrm{~m}$;

$* * *)$ The ratio $\mathrm{P} / \mathrm{H} \approx 1,3-1,5$ - corresponds to the value of the real module when moving a passenger car in the curve $\mathrm{R}=900-800 \mathrm{~m}$ at a speed of $\mathrm{V}=90 \mathrm{~km} / \mathrm{h}$.

\subsection{In the Second Stage of Solving the Problem We Consider the Deformation of the Rail Thread During Torsion Relative to the Longitudinal Axis X-X}

To solve the problem in full, taking into account the action of all forces on the length of the deformation of the torsion of the rail the equation of equilibrium of the rail thread in integral form, as already indicated from the beginning of the article is written by formula (11).

After some simplifications, which are also given at the beginning of the article, equation (11) is written in a simpler form (12).

According to experimental studies of prof. Yershkov [13] integral $\int_{-x_{\phi}}^{+x_{\phi}} \phi \cdot d x-$ is the area of the plot of the torsion angles plot $\omega_{\varphi}$ within the wavelength of the rail torsion (which practically corresponds to the length of the lateral bend of the rail).
That is: $\int_{-x_{\phi}}^{+x_{\phi}} \phi \cdot d x=\omega_{\phi}$

Prof. Yershkov in [13] found that:

$$
\begin{gathered}
\omega_{\phi}=\frac{(\delta-1) \cdot \omega_{y}^{\text {sol }}}{h^{\prime}}, \\
\omega_{y}^{\text {sol }}=\frac{\omega_{y}^{\text {head }}}{\delta},
\end{gathered}
$$

where $\omega_{y}^{\text {sol }}$ and $\omega_{y}^{\text {head }}$ - are the area of the diagrams of the transverse displacement of the sole and the head of the rail (with the joint action on the rail of horizontal and vertical forces $H$ and $P$ );

$h^{\prime \prime}$ - the distance between the points of measurement of the transverse displacement of the head and sole of the rail; $\delta-$ the ratio of the areas of the diagrams of the displacement of the 
head and sole of the rail, determined by the formula:

$$
\delta=\frac{\omega_{y}^{\text {head }}}{\omega_{y}^{\text {sol }}}
$$

(According to our researches [7, 15] for practical purposes, with a sufficient degree of accuracy, you can take a coefficient « $\delta$ » equal to the ratio of the transverse stiffness of the rail thread on the sole and on the head).

$$
\delta=\frac{\beta_{y}^{\text {sol }}}{\beta_{y}^{\text {head }}}
$$

Thus, the equation (12) after substituting the expression (53) and its solution relative to $U_{\varphi}$, will look like:

$$
U_{\phi}=\frac{H\left(h_{1}^{\prime}+h_{2}\right)-P \cdot e}{\omega_{\phi}}
$$

Next, substituting in equation (58) the value $\omega_{\varphi}$ of the formula (54), we obtain the following expression to determine the modulus of elasticity $U_{\varphi}$ of the subrail base when torsion the rail thread:

$$
U_{\phi}=\frac{H\left(h_{1}^{\prime}+h_{2}\right) \cdot h^{\prime \prime}}{(\delta-1) \cdot \omega_{y}^{s o l}}-\frac{P \cdot e \cdot h^{\prime \prime}}{(\delta-1) \cdot \omega_{y}^{s o l}}
$$

If we take into account that in real conditions of interaction between rolling stock and track the area of the plot of transverse displacements $\omega_{y}^{\text {sol }}$ is determined in the presence of vertical force $P$ and friction forces on the sole of the rail, then the ratio $H / \omega_{y}^{s o l}$ should be identified as the real value of the lateral modulus of elasticity of the subrail $U_{y}^{(f r)}$ that is determined taking into account the friction forces on the sole of the rail (see the author's articles $[7,15]$ on this problem):

$$
\frac{H}{\omega_{y}^{s o l}}=U_{y}^{(f r)}
$$

Then, substituting (60) in equation (59), we obtain in the final form a formula for determining the real (actual) value of the modulus of elasticity of the rail thread during torsion $\boldsymbol{U}_{\phi}^{(f r)}$ for the case of joint action of vertical and horizontal forces $(\mathrm{H}$ $\neq 0$ and $\mathrm{P} \neq 0$ ) and taking into account friction forces on the sole of the rail and the resistance forces of the subrail base with fasteners:

$$
\begin{aligned}
U_{\phi}^{(f r)} & =\frac{\left(h_{1}^{\prime}+h_{2}\right) \cdot h^{\prime \prime}}{\delta-1} \cdot U_{y}^{(f r)}- \\
& -\frac{P \cdot e \cdot h^{\prime \prime}}{(\delta-1) \cdot H} \cdot U_{y}^{(f r)}
\end{aligned}
$$

If the measurements of the transverse displacement of the rail head are determined opposite the point of application of the horizontal force $H$, and the displacement of the sole of the rail is determined close to the lower plane of the sole (which usually occurs in experiments), then we can take $h^{\prime \prime}=h_{1}^{\prime}+h_{2}$ and then formula (61) will take simpler look:

$$
\begin{gathered}
U_{\phi}^{(f r)}=\frac{\left(h^{\prime \prime}\right)^{2}}{\delta-1} \cdot U_{y}^{(f r)}- \\
-\frac{P \cdot e \cdot h^{\prime \prime}}{(\delta-1) \cdot H} \cdot U_{y}^{(f r)}
\end{gathered}
$$

The sign «-» in front of the 2 nd component in the right part of equations (61) and (62) corresponds to the scheme of loading the rail shown in Figure 2-b, when the moment of torsion of the external forces $M^{e x}$ tor is determined by the formula (5). For the case of applying a vertical load to the left of the axis of symmetry of the rail (in equations (61) and (62) should put a sign «+» before the second term in that case value «e» we take without any sign).

From the formula (61) it can be seen that the real (actual) modulus of elasticity of the rail thread during torsion $U_{\phi}^{(f r)}$ (for the case of joint action of vertical and horizontal lateral forces $(P \neq 0$ and $H \neq 0)$ ) functionally depends on the modulus of elasticity of the rail thread in transverse bending $U_{y}^{(f r)}$, as well as it depends on the ratio acting forces $P / H$ and from the eccentricity of the application «e» of the vertical force $P$, and also from the ratio of the stiffness of the rail thread on the head and sole during transverse bending $\delta=\frac{\beta_{y}^{\text {sol }}}{\beta_{y}^{\text {head }}}$.

Formula (61) in this form was obtained for the first time in studies of the deformation of the rail thread during torsion. This formula differs significantly from the results obtained in the studies of prof. Yershkov [13, 14] and, as will be shown below, formula (61) differs significantly from its other possible interpretations, including in function of the stiffness of the rail thread during torsion $\beta_{\varphi}$.

The results of calculations of real (actual) modulus of elasticity of the rail thread during torsion as a function $U_{\varphi}=f(P / H)$ for different designs of railway track with rails R65 on reinforced concrete and with rails R50 on wooden sleepers for different designs of fasteners are given in table 1.

The functional dependence of the modulus of elasticity of the rail thread during torsion $U_{\phi}^{f r}=f(P / H)$ for different track structures with rails R65, R50 on reinforced concrete and wooden sleepers is shown in Figure 5. For other designs of track constructions and for some values of vertical and horizontal loading on rails, which are closed to real forces of interaction $\left(P_{d y n} / H_{d y n}\right)$, under the results of calculations are given in the example at the end of this article. 


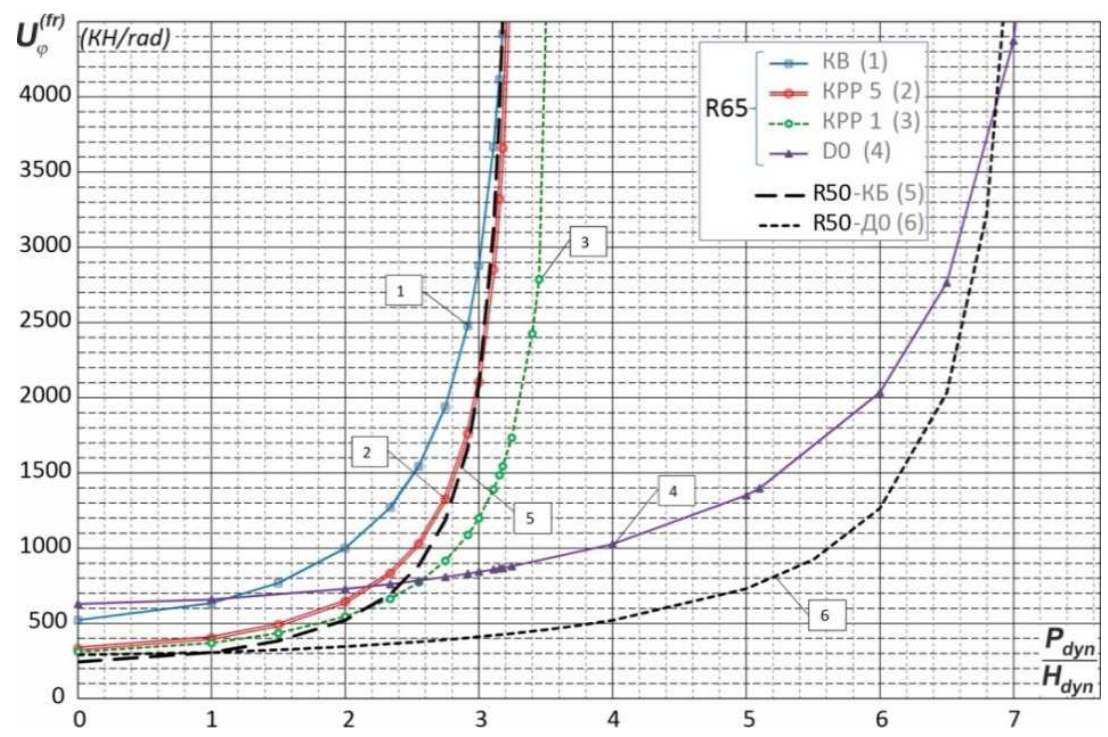

Figure 5. Graphs of functional dependences of modulus of elasticity of a subrail basis under torsion of a rail thread on a ratio of operating vertical and horizontal forces $U_{\phi}^{(f r)}=f\left(P_{d y n} / H_{d y n}\right)$ for track construction with rails $R 65$ and R50 on reinforced concrete and wooden sleepers at various designs of fastenings.

\subsection{At the Next Stage We Turn to the Determining of Another Important Characteristic - the Stiffness of the Rail Thread During Torsion $\left(\beta_{\varphi}\right)$}

From the classical theory of torsion of the rods [19] there is a formula for determining the angle of turn of the rod is known which has the form:

$$
\phi=\frac{M_{t o r}^{e x}}{\beta_{\phi}}
$$

where $\beta_{\varphi}$ - the stiffness of the rod during torsion;

$M_{t o r}^{e x}-$ torque moment of external forces (determined by the formula (5)).

When considering the horizontal bending and torsion of the rail thread is not attached to the supports on the action of the lateral transverse force $H$ and the torque moment caused $M_{t o r}^{e x}$ by the action of the lateral force $H$ and the eccentrically applied vertical load $P$ in [13] prof. Yershkov obtained the following relationship between the angle of turn of the rail and the torque moment $M_{\text {tor }}^{e x}$ applied to the rail (for the calculated cross section at the place of application of torque moment):

$$
\phi=\frac{M_{t o r}^{e x}}{2 D \cdot h_{Q}^{2} \cdot r_{1} \cdot r_{2} \cdot\left(r_{1}+r_{2}\right)},
$$

where: $h_{Q}$ - the distance between the centers of gravity of the head and sole;

$D$ - rigidity of the rail during bending torsion of the head and sole of the rail relative to its neck (according the formula prof. Tymoshenko $[8,9])$.

$$
D=E \frac{I_{z}^{\text {head }} \cdot I_{z}^{\text {sol }}}{I_{z}^{\text {head }}+I_{z}^{\text {sol }}}
$$

As can be seen from the comparison of formulas (63) and (64) that denominator in the expression (64):

$$
\beta_{\phi}=2 D \cdot h_{Q}^{2} \cdot r_{1} \cdot r_{2}\left(r_{1}+r_{2}\right)
$$

this is the stiffness of the rail thread during torsion $\beta_{\varphi}$, which lies freely and is not fixed on the rail supports, under the action on it the torque moment from horizontal lateral force $H$ and from the eccentrically applied vertical force $P$. And in that case the vertical bending of the rail thread from the force $P$ is not taken into account and the friction forces on the sole between the rail and the rail supports are not taken into account too.

In expressions (64) and (66) in addition to the already mentioned characteristics $D$ and $h_{Q}$ there are very important coefficients $r_{1}$ and $r_{2}$, which are defined in the studies of prof. Yershkov [13, 14] as: $r_{1}$ - coefficient characterizing the bending-torsional rigidity of the rail, which is determined by the formula:

$$
r_{1}=\sqrt{\frac{C}{D h_{Q}^{2}}}
$$

$r_{2}$ - the coefficient of relative stiffness of the rail base and the rail during torsion, which is determined by the formula:

$$
r_{2}=\sqrt{\frac{U_{\phi}}{C}}
$$

Based on the results of research [13, 14] prof. Yershkov obtained for the typical design of the track on wooden sleepers 
with rails types $\mathrm{R} 43$ and $\mathrm{R} 50$ ratio: $r_{2} / r_{1} \approx 0,15$. Therefore, after some transformations and substitution into expression (64), the value $r_{2}=0,15 \cdot r_{1}$, formula for the angle of turn of the rail thread in [14] is reduced to the form:

$$
\phi=\frac{M_{t o r}^{e x}}{2,30 \cdot D \cdot h_{Q}^{2} \cdot r_{1}^{2} \cdot r_{2}}
$$

Thus, the expression for the stiffness of the rail thread $\beta_{\varphi}$ in the final version of prof. Yershkov [14] is reduced to the form:

$$
\beta_{\phi}=2,30 \cdot C \cdot \sqrt{\frac{U_{\phi}}{C}}
$$

And from the expression (70) as a result the formula expressing dependence between the modulus of elasticity of a subrail basis at torsion $\left(U_{\varphi}\right)$ and stiffness of a rail thread at torsion $\left(\beta_{\varphi}\right)$ is deduced in the following form:

$$
U_{\phi}=\frac{1}{5,30 \cdot C} \beta_{\phi}^{2}
$$

The formula (71) was proposed by prof. Yershkov as universal for determining the relationship between the modulus of elasticity of the sub-rail base in torsion $\left(U_{\varphi}\right)$ and the stiffness of the rail thread in torsion $\left(\beta_{\varphi}\right)$ for all types of rails laid on wooden sleepers, regardless of the design of rail fasteners. And in that case it was proposed to determine the stiffness of the rail thread by the formula (66).

The formula (71) after the publication of prof. Yershkov's researches in [13, 14] in 1960 became widely known and began to be used in the calculation stresses in rails taking into account torsion deformations. In particular, this technique formed the basis of calculations of reference data on the torsional characteristics of the rails for the «Handbook of Railway Engineer» in 1972 [17] and was used in other widely published publications $[18,2]$.

However, our new researches (2012-2016) [6, 7, 15] has shown that the use of the above methodology is not correct and requires significant adjustments in general, including to ensure the correctness of the final results in relation to modern structures of the upper structure of the track.

1) First of all it is necessary to note that accepted prof. Yershkov in $[13,14]$ used the constant ratio of coefficients $r_{2} /$ $r_{1} \approx 0,15$ incorrectly for different types of rails, for different diagrams of laying sleepers and, moreover, for different track designs.

The results of our researches showed that the value of the ratio $\left(r_{2} / r_{1} \approx 0,15\right)$ can be taken only for the construction of the track on wooden sleepers with rails types R43 and R50 (with which prof. Yershkov just conducted experimental research). For example, for the same track design on wooden sleepers with a sleeve diagram of 1840 sleep $/ \mathrm{km}$ for rails UIC60 should take the ratio $r_{2} / r_{1} \approx 0,16$ and for rails R65 it should be taken $\left(r_{2} / r_{1} \approx 0,17\right)$. When changing the diagram of sleepers, the ratio should also change in proportion to the change in the coefficient $r_{2}$. The results of the calculations showed that even minor inaccuracies in the choice of the initial ratio $r_{2} / r_{1}$ ultimately lead to significant errors in determining the desired torsional characteristics $\beta_{\varphi}$ and accordingly: $U_{\varphi} ; U_{\phi}^{(f r)} ; \beta_{\phi}^{(f r)}$.

It is easy to show that the original formula (66), which is the stiffness of the rail thread during torsion $\beta_{\varphi}$ and after transformations is reduced to the final form (70), will have a different final form, if we substitute other ratios of coefficients, which unequal to $r_{2} / r_{1}=0,15$.

Namely: for rails of the R65 type calculations give other relation $\left(r_{2} / r_{1}=0,17\right)$ and therefore the final formula for definition $\beta_{\varphi}$ will get the following look:

$$
\begin{gathered}
\beta_{\phi}=2 D \cdot h_{Q}^{2} \cdot r_{1} \cdot r_{2} \cdot\left(r_{1}+r_{2}\right)= \\
=2,34 \cdot C \cdot \sqrt{\frac{U_{\phi}}{C}}
\end{gathered}
$$

Thus, the final formula (73), which expresses the relationship between the values $U_{\varphi}$ and $\beta_{\varphi}$ for rails type R65 will look like:

$$
U_{\phi}=\frac{\beta_{\phi}^{2}}{5,475 \cdot C}
$$

And for rails type UIC60 when $\left(r_{2} / r_{1}=0,16\right)$ the following expression will take place:

$$
\begin{gathered}
\beta_{\phi}=2 D \cdot h_{Q}^{2} \cdot r_{1} \cdot r_{2}\left(r_{1}+r_{2}\right)= \\
=2,32 \cdot C \cdot \sqrt{\frac{U_{\phi}}{C}}
\end{gathered}
$$

And final formula (75) for rails of the UIC60 type it will look like:

$$
U_{\phi}=\frac{\beta_{\phi}^{2}}{5,382 \cdot C}
$$

The corrections given in formulas (73), (75), (72) and (74), taking into account the large order of values of characteristics $\mathrm{C}$ and $\mathrm{D}$, significantly change the values of characteristics $U_{\varphi}$ and $\beta_{\varphi}$ for rails of types R65 and UIC60 in comparison with known formula (71) which was given in the works of prof. Yershkov and which can be used only for rails R43 and R50.

2) Also needs clarification of the physical content of the characteristics $\beta_{\varphi}$ in $U_{\varphi}$ in connection with the relationships between them.

The fact is that the characteristic of the stiffness of the rail thread $\beta_{\varphi}$ which is determined by formula (66), obtained from consideration only of the rail operating on horizontal bending under the influence of horizontal force $H$ and simultaneously on the torsion of the rail under torque moment $M^{e x}$ tor from eccentrically applied horizontal force $H$ and vertical force $P$. But in that case the vertical bending of the rail in this problem was not taken into account, and accordingly did not take into account the friction forces on 
the sole between the rail and the rail base from the action of the vertical force.

Thus, the characteristic $\beta_{\varphi}$ determined by formula (66) corresponds only to the stiffness of the rail thread, which not connected by fasteners to the base and which depends only on the shape of the rail and the stiffness of its cross-sectional elements. That is why the characteristic $U_{\varphi}$ in the formulas (71), (73), (75) - does not correspond to the modulus of elasticity of the real actual subrail base, because of it obtained from solving the problem, which did not take into account the effect of resistance of the subrail base to vertical bending and did not take into account the friction forces on the sole of the rail and the resistance of the rail fasteners. Therefore, it is correct to call this characteristic $U_{\varphi}$ - the modulus of elasticity in the torsion of a fictitious rail base. Our studies have shown that the values of the characteristics $\mathrm{U}_{\varphi}$ determined by formula (71) for rails R43 and R50 (or by formulas (73) and (75) for rails R65 and UIC60) can be correctly applied only in cases of absence vertical load on the rail (at $\mathrm{P}=0)$, which is practically non-existent in real conditions of interaction between rolling stock and track.

The actual real value of the stiffness of the rail thread when torsion $\boldsymbol{\beta}_{\phi}^{(r f)}$, taking into account its connections with the subrail base, should be determined from the other formulas of the form (76), (77), (78) after substitution in them instead of a fictitious modulus of elasticity during the torsion of the rail base $U_{\varphi}$, the values of the real actual modulus of elasticity of the rail base during the torsion of the rail thread $U_{\phi}^{(r f)}$, which are determined by formula (61) and accordingly differ for different types of rails, namely:

for rails type R50 and R43 by the formula:

$$
\beta_{\phi}^{(r f)}=\sqrt{5,30 \cdot C \cdot U_{\phi}^{(r f)}}
$$

for rails type $\mathrm{R} 65$ by the formula:

$$
\beta_{\phi}^{(r f)}=\sqrt{5,475 \cdot C \cdot U_{\phi}^{(r f)}}
$$

for rails type UIC60 according to the formula:

$$
\beta_{\phi}^{(f r)}=\sqrt{5,382 \cdot C \cdot U_{\phi}^{(f r)}}
$$

The results of verification calculations $[7,15]$ showed that the real actual values of the modulus of elasticity in torsion ( $U_{\phi}^{(r f)}$ ) are significantly greater than the values of the modulus of elasticity of the fictitious basis $\left(U_{\varphi}\right)$ and differ by about 2,0-3,5 times depending on the type of railway track structures - for real of ratios vertical and horizontal acting forces $P / H$. And the real values of stiffness of the rail thread during torsion $\beta_{\phi}^{(f r)}$ (taking into account its connections with the subrail base) differ in the direction of increase from the fictitious value of stiffness $\beta_{\varphi}$ - about 1,5-2,5 times for the actual operating ratios of vertical and horizontal forces $(P / H)$ also depending on the type of railway track structures.

\subsection{Calculation of Stresses and Strains in Rail Threads}

Only after determining the spatial characteristics of elasticity and stiffness of the rail thread and subrail base $U_{y}^{(f r)}, U_{\phi}^{(f r)}, \beta_{\phi}^{(f r)}, k_{y}^{(f r)} ; E I_{z}^{\text {rail }}, E I_{z}^{\text {head }}, E I_{z}^{\text {sol }}, D$, $I_{t o r}^{r a i l}, C$ that are found from consideration of the operation of the rail thread under conditions of joint action of vertical and horizontal forces and torsion, taking into account the fact that the characteristics of elasticity and stiffness of the same rail thread and subrail base at vertical bending of the rail thread as a long beam on an elastic base; which are known in advance - only after that, it is possible to proceed to the calculation of stresses and strains of the considered rail thread design.

Below we give the basic calculation formulas that determine the stresses, strains and transverse forces in the rails.

1. The angle of turn of the vertical axis of the rail relative to the center of rotation $(\cdot) 0$ is determined by the formula:

$$
\phi_{0}^{(f r)}=\frac{M_{t o r}^{e x}}{\beta_{\phi}^{(f r)}}
$$

2. Transverse horizontal displacement of the center $(\cdot) 0$ torsion of the rail (the same is the center of the bend on the rail thread) determined by the formula:

$$
y_{\text {torcent }}=y_{0}=\frac{H}{8\left(k_{y}^{(f r)}\right)^{3} \cdot E I_{\text {zrail }}}
$$

3. The transverse horizontal displacement of the top of the rail head is determined by the formula:

$$
y_{\text {head }}=y_{0}+h_{1}^{\prime} \cdot \phi_{0}^{(f r)}
$$

4. Transverse horizontal displacement of the bottom of the sole of the rail is determined by the formula:

$$
y_{\text {sol }}=y_{0}-h_{2} \cdot \phi_{0}^{(f r)}
$$

5. The summarized normal stresses in the rail head from the transverse bend in the horizontal plane and from the bending torsion of the head relative to the neck of the rail are determined by formulas:

$$
\left.\begin{array}{c}
\sigma_{\Sigma}^{\text {headedge }(\text { ex })}=-E \cdot \frac{I_{z}^{\text {rail }}}{W_{\text {head edge }}^{\text {rail }}} \cdot\left(\frac{d^{2} y}{d x^{2}}\right)- \\
-E \cdot \frac{I_{z}^{\text {head }}}{W_{\text {head edge }}^{\text {head }}} \cdot h_{Q 1} \cdot\left(\frac{d^{2} \phi}{d x^{2}}\right) \\
\sigma_{\Sigma}^{\text {headedge }(\text { in })}=+E \cdot \frac{I_{z}^{\text {rail }}}{W_{\text {head edge }}^{\text {rail }}} \cdot\left(\frac{d^{2} y}{d x^{2}}\right)+ \\
+E \cdot \frac{I_{z}^{\text {head }}}{W_{\text {head eadge }}^{\text {head }}} \cdot h_{Q 1} \cdot\left(\frac{d^{2} \phi}{d x^{2}}\right)
\end{array}\right\}
$$


6. The summarized normal stresses in the sole of the rail from the transverse bend in the horizontal plane and from the bending torsion of the sole relative to the neck of the rail are determined by the formulas:

$$
\left.\begin{array}{c}
\sigma_{\Sigma}^{\text {sol edge }(e x)}=-E \cdot \frac{I_{z}^{\text {rail }}}{W_{\text {soledge }}^{\text {rail }}} \cdot\left(\frac{d^{2} y}{d x^{2}}\right)+ \\
+E \cdot \frac{I_{z}^{\text {sol }}}{W_{\text {soledge }}^{\text {sol }}} \cdot h_{Q 2} \cdot\left(\frac{d^{2} \varphi}{d x^{2}}\right) \\
\sigma_{\Sigma}^{\text {soledge(in) }}=+E \cdot \frac{I_{z}^{\text {rail }}}{W_{\text {saledge }}^{\text {rail }}} \cdot\left(\frac{d^{2} y}{d x^{2}}\right)- \\
-E \cdot \frac{I_{z}^{\text {sol }}}{W_{\text {sol edge }}^{\text {sol }}} \cdot h_{Q 2} \cdot\left(\frac{d^{2} \varphi}{d x^{2}}\right)
\end{array}\right\}
$$

7. Tangential stresses in the head and in the sole of the rail are determined by the formulas:

$$
\left.\begin{array}{c}
\tau_{\max }^{\text {head }}=\frac{0,5 \cdot M_{t o r}^{e x} \cdot t_{\max }^{\text {head }}}{I_{c r}^{\text {rail }}} \\
\tau_{\max }^{\text {sol }}=\frac{0,5 \cdot M_{t o r}^{e x} \cdot t_{\max }^{\text {sol }}}{I_{c r}^{\text {rail }}}
\end{array}\right\}
$$

8. Transverse forces $\mathrm{Q}$ are determined by the formulas:

$$
\left.\begin{array}{c}
\text { for rail head } \\
Q_{\text {head }}=E I_{z}^{\text {head }} \cdot h_{Q 1} \cdot \frac{d^{3} \phi}{d x^{3}}= \\
=E I_{z}^{\text {head }} \cdot h_{Q 1} \cdot \frac{0,5\left(H \cdot h_{1}^{\prime}-P \cdot e\right)}{D \cdot h_{Q}^{2}} \\
\text { for the sole of the rail } \\
Q_{\text {sol }}=E I_{z}^{\text {sol }} \cdot h_{Q 2} \cdot \frac{d^{3} \phi}{d x^{3}}= \\
=E I_{z}^{\text {sol }} \cdot h_{Q 2} \cdot \frac{0,5\left(H \cdot h_{1}^{\prime}-P \cdot e\right)}{D \cdot h_{Q}^{2}}
\end{array}\right\}
$$

9. The second derivatives $\left(\frac{d^{2} y}{d x^{2}}\right) ;\left(\frac{d^{2} \phi}{d x^{2}}\right)$ and the third derivative $\left(\frac{d^{3} \phi}{d x^{3}}\right)$ are determined by the formulas:

$$
\frac{d^{2} y}{d x^{2}}=y^{\prime \prime}=-\frac{H}{4 \cdot k_{y}^{f r} \cdot E I_{z}^{r a i l}}
$$

$$
\left.\begin{array}{c}
\text { for rail head } \\
\frac{d^{2} \phi}{d x^{2}}=\phi^{\prime \prime}=-\frac{Q \cdot h_{Q}}{E I_{z}^{\text {head }} \cdot h_{Q 1}} \\
\text { for the sole of the rail } \\
\frac{d^{2} \phi}{d x^{2}}=\phi^{\prime \prime}=-\frac{Q \cdot h_{Q}}{E I_{z}^{\text {sol }} \cdot h_{Q 2}}
\end{array}\right\}
$$

After substitution $Q$ it will be the same for the head and for the sole.

$$
\frac{d^{2} \phi}{d x^{2}}=-\frac{0,5\left(H \cdot h_{1}^{\prime}-P \cdot e\right)}{D \cdot h_{Q}}
$$

The third derivatives

$$
\frac{d^{3} \phi}{d x^{3}}=\phi^{\prime \prime \prime}=\frac{0,5\left(H \cdot h_{1}^{\prime}-P \cdot e\right)}{D \cdot h_{Q}^{2}}
$$

\section{Example of Calculation of the Stress - Strain State of the Rail Thread According to the New Method}

It is necessary to determine the stresses and strains in the rails with the combined action of vertical dynamic force $\left(P_{d y n}\right)$ and horizontal lateral dynamic force $\left(H_{d y n}\right)$ for a given track structures.

In the calculations, the maximum values of stresses and strains are determined, which arise in the edges of the head and sole of the rail during joint vertical and lateral horizontal bending of the rail thread in conjunction with simultaneous torsion.

Once again, we note that the calculation of stresses and strains in the rails of the railway track presented in this article applies only to the lateral transverse bending and torsion of the rail thread, which occurs under the action of lateral horizontal force $H_{d y n}$ and torque moment $M_{t o r}^{e x}$. To take into account stresses and strains in rail threads from vertical bending from the action of vertical dynamic forces $P_{d y n}$, it is necessary to add to the results of these calculations the results of calculations performed according to the current standard engineering calculation methods, for example "Rules of calculation of railway track strength" [4]. Separately it should be noted, that when calculating the stresses in the rails according to the method [4] it should be excluded taking into account so-called coefficient $f$, which is designed to take into account the action of horizontal forces, that is, it is necessary to calculate the maximum stresses from the force $P_{d y n}$ only near the vertical axis of the rail $\mathrm{z}-\mathrm{z}$ on the top of the head and on the bottom of the rail sole.

The scheme for summing the maximum stresses in the head and sole of the rail from the acting forces $P_{d y n}$ and $H_{d y n}$ is adopted in accordance with Figure 6. 


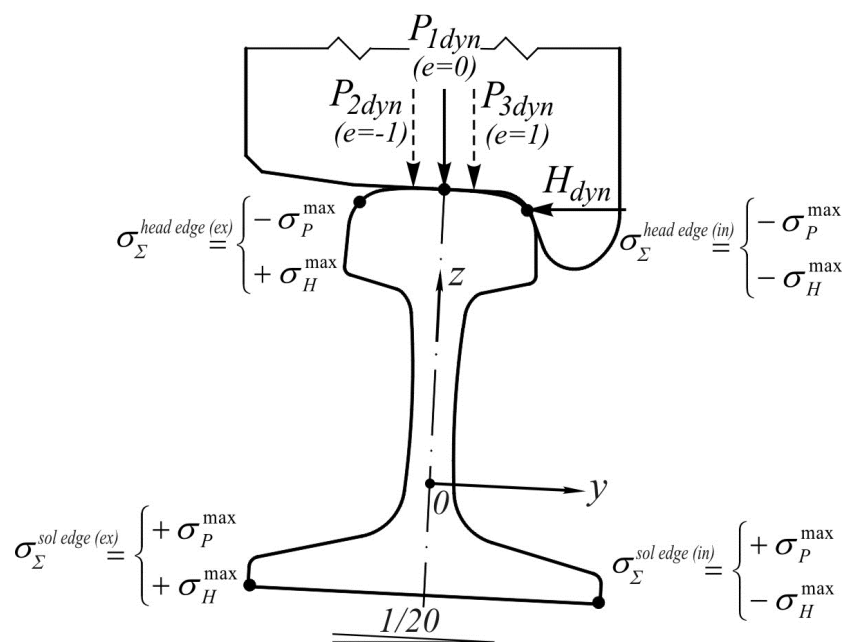

Figure 6. Scheme of distribution of stresses acting in the rail from the action $P_{d y n}$ and $H_{d y n}$ (on figure 6 are marked: stretching $(+\sigma)$, pressure $(-\sigma)$ ).

The summation of normal stresses in the lateral edges of the head and sole of the rail from the lateral bending by the force $H_{d y n}$ and vertical bending by the force $P_{d y n}$ must be performed taking into account the signs of stresses (Figure 6).
(Normal stresses from the action of longitudinal forces are determined separately; according to special methodic for calculating the railway track (look $[4,15]))$.

\subsection{Initial Data for Calculations}

Rail parameters are given in table 2.

Railway track:

1) rails $\mathrm{R} 65$ on concrete sleepers; in the curve $\mathrm{R}=800 \mathrm{~m}$; sleepers diagram $1840 \mathrm{sl} . / \mathrm{km}$; fasteners KB, KPP-5;

2) rails $\mathrm{R} 50$ on concrete sleepers and wooden sleepers, both constructions in the curve $\mathrm{R}=800 \mathrm{~m}$; sleepers diagram for concrete sl. $1840 \mathrm{sl} . / \mathrm{km}$, for wooden sl. $2000 \mathrm{sl} . / \mathrm{km}$; fasteners: for concrete sl. KB, for wooden sl. D0.

Rolling stock: freight 4-axle car; dynamic forces from one wheel $\mathrm{P}_{\text {dyn }}=16350 \mathrm{~kg}, \mathrm{H}_{\mathrm{dyn}}=7000 \mathrm{~kg}$; eccentricity for $\mathrm{P}_{\mathrm{dyn}}$ is $\mathrm{e}_{1}=0 \mathrm{~cm} ; \mathrm{e}_{2}=-1 \mathrm{~cm}$; eccentricity for $\mathrm{H}_{\mathrm{dyn}}$ is $\mathrm{h}_{1}{ }^{\prime}$.

Characteristics of the railway track:

1) vertical modulus of elasticity $\left(U_{z}\right)^{1)}{ }^{2}$ ): for concrete sleepers with fasteners $\mathrm{KB} \mathrm{U}_{\mathrm{z}}=677 \mathrm{~kg} / \mathrm{cm}^{2}$; for concrete sleepers with fasteners KPP-5 $U_{z}=692 \mathrm{~kg} / \mathrm{cm}^{2}$; for wooden sleepers with fasteners D $0 \mathrm{U}_{\mathrm{z}}=261 \mathrm{~kg} / \mathrm{cm}^{2}$;

Table 2. Parameters of rails.

\begin{tabular}{|c|c|c|}
\hline Rail parameters & R65 & R50 \\
\hline 1. Cross-sectional area $\mathrm{F}, \mathrm{cm}^{2}$ & 82,649937 & 65,998257 \\
\hline \multicolumn{3}{|l|}{ 2. Distance from the center of gravity, $\mathrm{cm}$ : } \\
\hline to the bottom of the sole & 8,135 & 7,054 \\
\hline to the top of the head & 9,865 & 8,146 \\
\hline \multicolumn{3}{|l|}{ 3. Distance from the center of torsion, $\mathrm{cm}$ : } \\
\hline to the bottom of the sole $h_{2}$ & 4,066 & 4,017 \\
\hline to the top of the head $h_{1}$ & 13,934 & 11,183 \\
\hline \multicolumn{3}{|l|}{ 4. The moment of inertia about the vertical axis, $\mathrm{cm}^{4}$ : } \\
\hline all rail $I_{z}^{\text {rail }}$ & 567,640 & 374,921 \\
\hline head rail $I_{z}^{\text {head }}$ & 111,501 & 91,140 \\
\hline sole rail $I_{z}^{\text {sol }}$ & 444,370 & 277,960 \\
\hline 5. The moment of inertia about the horizontal axis $I_{y}^{r a i l}, \mathrm{~cm}^{4}$ & 3543,796 & 2018,440 \\
\hline \multicolumn{3}{|l|}{ 6. Moment of resistance, $\mathrm{cm}^{3}$ : } \\
\hline rail about edge of the head $W^{\text {rail }}{ }_{\text {head edge }}$ & 151,371 & 104,144 \\
\hline rail about edge of the sole $W^{\text {rail }}$ sole edge & 75,184 & 56,806 \\
\hline head of rail about edge of the head $W_{\text {head edge }}^{\text {head }}$ & 29,734 & 25,316 \\
\hline sole of rail about edge of the sole $W_{\text {sole ele edge }}^{\text {sol }}$ & 59,249 & 42,115 \\
\hline 7. The moment of inertia during rail torsion $r^{r a i l}$ tor, $\mathrm{cm}^{4}$ & 287,486 & 200,799 \\
\hline \multicolumn{3}{|l|}{ 9. Rigidity of the cross section of the rail: } \\
\hline during pure torsion $C, \mathrm{~kg} \cdot \mathrm{cm}^{2} / \mathrm{rad}$ & $232,20027 \cdot 10^{6}$ & $162,18388 \cdot 10^{6}$ \\
\hline \multicolumn{3}{|l|}{ 10. Geometric characteristics of rails } \\
\hline$h, \mathrm{~cm}$ & 18,000 & 15,200 \\
\hline$h_{l}, \mathrm{~cm}$ & 13,934 & 11,183 \\
\hline$h_{2}, \mathrm{~cm}$ & 4,066 & 4,017 \\
\hline$h_{1}^{\prime}, \mathrm{cm}$ & 12,364 & 9,643 \\
\hline$h_{Q}, \mathrm{~cm}$ & 14,772 & 12,221 \\
\hline$h^{\prime \prime}, \mathrm{cм}\left(h^{\prime \prime}=h_{1}^{\prime}+h_{2}\right)$ & 16,430 & 13,660 \\
\hline$h_{Q l}, \mathrm{~cm}$ & 11,809 & 9,203 \\
\hline$h_{Q 2}, \mathrm{~cm}$ & 2,963 & 3,018 \\
\hline
\end{tabular}

2) horizontal (lateral) stiffness of the rail thread and horizontal (lateral) modulus of elasticity of the rail thread for R65, KB, concrete sleepers: $U_{\mathrm{y}-0}=255,812 \mathrm{~kg} / \mathrm{cm}^{2}{ }^{1)}{ }^{2)}$, $\beta_{\text {head }}=19200 \mathrm{~kg} / \mathrm{cm}^{1)}, \beta_{\text {sol }}=44640 \mathrm{~kg} / \mathrm{cm}^{1)}$; for R65, KPP-5, concrete sleepers: $U_{\mathrm{y}-0}=349,472 \mathrm{~kg} / \mathrm{cm}^{2}{ }^{1)}{ }^{2)}, \beta_{\text {head }}=18800$ $\mathrm{kg} / \mathrm{cm}^{1)}, \beta_{\mathrm{sol}}=72440 \mathrm{~kg} / \mathrm{cm}^{1)}$; for R50, KB, concrete sleepers: 
$\mathrm{U}_{\mathrm{y}-0}=178,7 \mathrm{~kg} / \mathrm{cm}^{2}{ }^{1)}{ }^{2)}, \beta_{\text {head }}=13700 \mathrm{~kg} / \mathrm{cm}^{1)}, \quad \beta_{\mathrm{sol}}=32500$ $\mathrm{kg} / \mathrm{cm}^{1)}$; for R50, D0, wooden sleepers: $\mathrm{U}_{\mathrm{y}-0}=155,51 \mathrm{~kg} / \mathrm{cm}^{21)}$ ${ }^{2)}, \beta_{\text {head }}=13500 \mathrm{~kg} / \mathrm{cm}^{1)}, \beta_{\text {sol }}=27000 \mathrm{~kg} / \mathrm{cm}^{1)}$.

1) obtained by experimental researches;

2) obtained by theoretical calculations.

The calculation is performed on the action of horizontal transverse force and torsion in accordance with the calculation scheme presented in Figure 2.

\subsection{Algorithm for Performing Calculations}

The initial data are set (see above), after which the calculation is performed in the following sequence.

1. The modulus of shift elasticity is calculating according to the formula:

$$
G=E / 2(1+\mu) ; E-\text { elastic modulus of steel; }
$$

$\mu$ - Poisson ratio of steel.

It takes for rail steel $E=2,1 \cdot 10^{6} \mathrm{~kg} / \mathrm{cm}^{2} ; \mu=0,3$.

2 . The rigidity of the rail during bending rotation head and sole of the rail relative to its neck is calculated according to formula prof. Timoshenko:

$$
D=E \cdot\left(I_{z}^{\text {head }} \cdot I_{z}^{\text {sol }}\right) /\left(I_{z}^{\text {head }}+I_{z}^{\text {sol }}\right) .
$$

3. The rigidity of the cross section of the rail during pure torsion by the formula (according to Saint-Venant):

$$
C=F^{4} \cdot G /\left(4 \cdot \pi^{2} \cdot I_{p}\right) ; I_{p}=I_{z}^{\text {rail }}+I_{y}^{\text {rail }} .
$$

4. The moment of inertia of the rail during its torsion calculated by the formula from «Resistance of materials»:

$$
I_{\text {tor }}^{\text {rail }}=C / G
$$

5. Stiffness of the rail thread during torsion $\beta \varphi$ (fictitious value according to the formula (66)).

6. Modulus of elasticity of a rail at torsion $U \varphi$ (fictitious value according to the formula (71)).

7. External torque moment according to the formula (5): $M_{\text {tor }}^{e x}=H \cdot h_{1}^{\prime}-P \cdot e$.

8. The modulus of elasticity of the subrail base with horizontal bending of the rail thread $U_{y-0}$ (without taking into account the action of vertical forces and friction forces on the sole of the rail at $H \neq 0$ та $P=0$ ) according to experiments to determine the stiffness of the rail threads.

8.1. Horizontal transverse displacement of the center of bending of the rail is calculated (using the ratios (16) and (21)) by the formula: $y_{0}^{\text {centrbend }}=\frac{y_{0}^{\text {sol }}\left(h_{1}^{\prime}+\delta \cdot h_{2}\right)}{h_{1}^{\prime}+h_{2}}$,

where $y_{0}^{\text {sol }}$ - accepted from the experiment (at $H \neq 0, P=0$ ) when is known values $\beta_{\text {sol }}, \beta_{\text {head }}$ and $\delta$.

8.2. Relative stiffness coefficient $k_{y 0}$ (at $H \neq 0, P=0$ ) is calculated by the formula (31) (at a known value $y_{0}^{\text {centerbend }}$ ).

8.3. The modulus of elasticity of the subrail base $\mathrm{U}_{\mathrm{y}-0}$ by the formula (29) (at $\mathrm{H} \neq 0$ and $\mathrm{P}=0$ ).

9. Calculation of the coefficient «a» and the length $\mathrm{x}_{\mathrm{fr}}$ of the half-wave of the friction section on the sole of the rail under the combined action of vertical and horizontal forces.

9.1. Coefficients of relative stiffness of the base and rail in the horizontal and vertical planes $\mathrm{k}_{\mathrm{z}}, \mathrm{k}_{\mathrm{y}}$ are calculated by formulas: $k_{z}=\sqrt[4]{U_{z} /\left(4 E I_{y}\right)} ; k_{y}=\sqrt[4]{U_{y} /\left(4 E I_{z}\right)}$.

9.2. According to the calculation scheme (Figure 2-a), a predetermined maximum half-wavelength of propagation along the $x-x$ axis of elastic vertical deflections $x_{z}^{\max }=+\pi / k_{z}$ is taken. With a known abscissa $x_{z}^{\max }$, the minimum ordinate of the vertical deflections from the vertical force $P=1$ is also known and is $\eta_{z}^{\max }=-0,0432$. Next, considering the relation (26) and substituting the known ordinate $\eta_{z}^{0}$ for any value $\mathrm{P}$, we determine the unknown ordinates of the plot of transverse horizontal deflections $\eta_{y 0}$ (along the line of the centers of bending $x$-x) with the combined action of forces $P$ and $H$ for any ratio $P_{i} / H_{i}$. To determine the transverse displacements along the line of centers of the sole of the rail thread, you need to perform similar calculations by the formula (32).

9.3. After that, you need to determine the value of $x_{f r}$ - the length of the elastic half-wave of the friction section on the sole of the rail at horizontal lateral bending of the rail from the joint action of $H$ and $P . x_{f r}$ is determined by the formula $x_{f r}=3 \pi /\left(4 k_{y}\right)-\Delta$, where $\Delta$ is the shortening at half-wave of the horizontal lateral bending of the rail thread under the joint action of $H \neq 0$ and $P \neq 0$ in comparison with the lateral bending under the action of only $H \neq 0$ and the absence of $P=0$.

9.4. After that, the coefficient "a" is determined by formula (44) for any given ratios of vertical and horizontal forces $P / H$.

10. The modulus of horizontal elasticity of the track $U_{y-f r}$ by the formula (48) (at different values $H \neq 0$ and $P \neq 0$ ).

11. The coefficient of relative stiffness $k_{y-f r}$ of the base and rail in the horizontal plane, taking into account the joint action of $P$ and $H$, by the formula $k_{y}^{f r}=\sqrt[4]{U_{y}^{f r} /\left(4 E I_{z}\right)}$.

12. Real modulus of elasticity of the rail thread during torsion $U_{\varphi-f r}$ by the formula (61).

13. Real value of the stiffness of the rail $(z-z)$ thread at torsion $\beta_{\phi}^{f r}$ by formula (77) or (78) or (76).

14. Angle of turn $\phi_{0}^{f r}$ of the vertical axis of the rail $(z-z)$ by the formula (79).

15. After that are calculated elastic deflections of the head and sole of the rail.

15.1. Horizontal displacement of the torsion center $y_{0}^{f r}$ (at $H \neq 0$ та $P \neq 0$ ) by the formula (30).

15.2. Horizontal displacements of the top of the head $y_{\text {head }}^{f r}$ and sole $y_{\text {sol }}^{f r}$ of the rail by the formulas: $y_{\text {head }}^{f r}=y_{0}^{f r}+h_{1}^{\prime} \cdot \phi_{0}^{f r} ; y_{\text {sol }}^{f r}=y_{0}^{f r}-h_{2} \cdot \phi_{0}^{f r}$.

16. Derivatives from displacements are calculated:

16.1. The second derivative of horizontal displacement $y^{\prime \prime}$ by the formula (87).

16.2. The second derivative of the angle of turn $\varphi^{\prime \prime}$ by the 
formula (89).

16.3. Third derivative of the angle of turn $\varphi^{\prime \prime}$ by the formula (90).

17. Tangential stresses in the head and sole of the rail by formulas (85).

18. Transverse forces are calculated by formulas (86).

19. Summarized normal stresses in the head and sole of the rail from bending in the horizontal plane and bending torsion are determined by the formulas (83) and (84).

\subsection{Results of Calculations}

Using the algorithm described above, the calculations were performed by computer and the results were obtained below in table 3 (For eccentricity of the force $(P) e=0$ and $e=-1 \mathrm{~cm})$.

The calculation of stresses and strains in the rails described in this example applies only to the lateral transverse bending and torsion of the rail thread. To determine the summarized normal stresses in the rail thread, taking into account the action of vertical dynamic forces $P_{d y n}$, it is necessary to add to the results of these calculations the calculated stresses determined by the method, thread described in standard methodics $[4,15]$.

Table 3. The results of calculations the lateral transverse bending and torsion of the rail thread.

\begin{tabular}{|c|c|c|c|c|c|c|c|c|c|c|c|}
\hline $\mathbf{U}_{\mathbf{z}}$ & $\mathbf{k}_{\mathbf{z}}$ & $\mathbf{U}_{\mathbf{y} \mathbf{0}}$ & $\mathbf{k}_{\mathbf{y} \mathbf{0}}$ & $\mathbf{U}_{\mathbf{y}}(\mathbf{f r})$ & $\mathbf{k}_{\mathbf{y}}(\mathbf{f r})$ & $\boldsymbol{\beta}_{\varphi}$ & $\boldsymbol{\beta}_{\varphi(\mathrm{fr})}$ & $\mathbf{U}_{\varphi}$ & $\mathbf{U}_{\varphi}(\mathbf{f r})$ & $\mathbf{M}_{\text {tor }}^{\mathbf{e x}}$ & $\varphi_{0}(\mathbf{f r})$ \\
\hline 677 & 0.0122 & 255.8 & 0.01521 & 623.389 & 0.01901 & 6964421.1 & 12706696 & 38152.5 & 127004.2 & 86548 & 0.006811 \\
\hline $\mathrm{a}$ & $\mathrm{X}_{\mathrm{fr}}$ & $\mathrm{y}_{0}$ & $\mathrm{y}_{\text {head }}$ & $\mathrm{y}_{\mathrm{sol}}$ & $\tau_{\text {head }}$ & $\tau_{\text {sol }}$ & $\sigma_{\text {head }}^{\text {edge(ex) }}$ & $\sigma_{\text {head }}^{\text {edge(in) }}$ & $\sigma_{\text {sol }}^{\text {edge(ex) }}$ & $\sigma_{\text {sol }}^{\text {edge(in) }}$ & $\mathrm{Q}$ \\
\hline 0.8414 & 95.0634 & 0.10676 & 0.190974 & 0.0790655 & 630.702 & 340.188 & 2063.315 & -2063.315 & 493.661 & -493.661 & 2928.139 \\
\hline \multicolumn{12}{|c|}{ R-65, KPP-5, Diagram 1840, e $=0 \mathrm{~cm}, \mathrm{P}=16350 \mathrm{~kg}, \mathrm{H}=7000 \mathrm{~kg}, \mathrm{P} / \mathrm{H}=2.336, \mathrm{f}=0.32, \mathrm{e}=0 \mathrm{~cm}, \delta=3.85$} \\
\hline $\mathrm{U}_{\mathrm{z}}$ & $\mathrm{k}_{\mathrm{z}}$ & $\mathrm{U}_{\mathrm{y} 0}$ & $\mathrm{k}_{\mathrm{y} 0}$ & $\mathrm{U}_{\mathrm{y}}(\mathrm{fr})$ & $\mathrm{k}_{\mathrm{y}}(\mathrm{fr})$ & $\beta_{\varphi}$ & $\beta_{\varphi(\mathrm{fr})}$ & $\mathrm{U}_{\varphi}$ & $\mathrm{U}_{\varphi}(\mathrm{fr})$ & $\mathrm{M}_{\text {tor }}^{\mathrm{ex}}$ & $\varphi_{0}(\mathrm{fr})$ \\
\hline 692 & 0.0123478 & 349.472 & 0.0164538 & 877.925 & 0.0207146 & 6964421.126 & 10281756.05 & 38152.512 & 83154.8689 & 86548 & 0.0084176 \\
\hline 0.80534 & 87.5008 & 0.082582 & 0.186658 & 0.0483559 & 630.702 & 340.188 & 2013.466 & -2013.466 & 393.299 & -393.299 & 2928.139 \\
\hline \multicolumn{12}{|c|}{$\mathrm{R}-50, \mathrm{~KB}$, Diagram 1840, e $=0 \mathrm{~cm}, \mathrm{P}=16350 \mathrm{~kg}, \mathrm{H}=7000 \mathrm{~kg}, \mathrm{P} / \mathrm{H}=2.336, \mathrm{f}=0.3, \delta=2.372$} \\
\hline $\mathrm{U}_{\mathrm{z}}$ & $\mathrm{k}_{\mathrm{z}}$ & $\mathrm{U}_{\mathrm{y} 0}$ & $\mathrm{k}_{\mathrm{y} 0}$ & $\mathrm{U}_{\mathrm{y}}(\mathrm{fr})$ & $\mathrm{k}_{\mathrm{y}}(\mathrm{fr})$ & $\beta_{\varphi}$ & $\beta_{\varphi(\mathrm{fr})}$ & $\mathrm{U}_{\varphi}$ & $\mathrm{U}_{\varphi}(\mathrm{fr})$ & $\mathrm{M}_{\text {tor }}^{\mathrm{ex}}$ & $\varphi_{0}(\mathrm{fr})$ \\
\hline 677 & 0.0141359 & 178.7 & 0.0154339 & 510.395 & 0.0200642 & 4856680.891 & 7724470.46 & 27440.714 & 69415.0592 & 67501 & 0.0087386 \\
\hline $\mathrm{a}$ & $X_{\text {fr }}$ & $\mathrm{y}_{0}$ & $\mathrm{y}_{\text {head }}$ & $\mathrm{y}_{\mathrm{sol}}$ & $\tau_{\text {head }}$ & $\tau_{\mathrm{sol}}$ & $\sigma_{\text {head }}^{\text {edge(ex) }}$ & $\sigma_{\text {head }}^{\text {edge(in) }}$ & $\sigma_{\text {sol }}^{\text {edge(ex) }}$ & $\sigma_{\text {sol }}^{\text {edge(in) }}$ & Q \\
\hline 0.927452 & 101.453 & 0.13759 & 0.221856 & 0.102487 & 638.708 & 336.162 & 2170.74 & -2170.74 & 734.238 & -734.238 & 2762.275 \\
\hline \multicolumn{12}{|c|}{ R-50, D0, Diagram 1840, e=0 cm, $\mathrm{P}=16350 \mathrm{~kg}, \mathrm{H}=7000 \mathrm{~kg}, \mathrm{P} / \mathrm{H}=2.336, \mathrm{f}=0.15, \delta=2.0$} \\
\hline a & $\mathrm{X}_{\mathrm{fr}}$ & & $\mathrm{y}_{\text {head }}$ & $\mathrm{y}_{\text {sol }}$ & $\tau_{\text {head }}$ & $\tau_{\text {sol }}$ & $\sigma_{\text {head }}^{\text {edge(ex) }}$ & $\sigma_{\text {head }}^{\text {edge(in) }}$ & $\sigma_{\text {sol }}^{\text {edge }(\mathrm{e}}$ & $\sigma_{\text {sol }}^{\text {edge(in) }}$ & Q \\
\hline 0.57964 & 60.8747 & 0.28298 & 0.399328 & 0.234513 & 638.708 & 336.162 & 2398.297 & -2398.297 & 1151.426 & -1151.426 & 2762.275 \\
\hline \multicolumn{12}{|c|}{ For $e=-1 \mathrm{~cm}$} \\
\hline \multicolumn{12}{|c|}{$\mathrm{R}-65, \mathrm{~KB}$, Diagram 1840, e=-1 cm, $\mathrm{P}=16350 \mathrm{~kg}, \mathrm{H}=7000 \mathrm{~kg}, \mathrm{P} / \mathrm{H}=2.336, \mathrm{f}=0.3, \delta=2.325$} \\
\hline $\mathrm{U}_{\mathrm{z}}$ & $\mathrm{k}_{\mathrm{z}}$ & $\mathrm{U}_{\mathrm{y} 0}$ & $\mathrm{k}_{\mathrm{y} 0}$ & $\mathrm{U}_{\mathrm{y}}(\mathrm{fr})$ & $\mathrm{k}_{\mathrm{y}}(\mathrm{fr})$ & $\beta_{\varphi}$ & $\beta_{\varphi(\mathrm{fr})}$ & $\mathrm{U}_{\varphi}$ & $\mathrm{U}_{\varphi}(\mathrm{fr})$ & $\mathrm{M}_{\text {tor }}^{\mathrm{ex}}$ & $\varphi_{0}(\mathrm{fr})$ \\
\hline 677 & 0.0122803 & 255.812 & 0.0152192 & 623.389 & 0.0190152 & 6964421.126 & 12761550.49 & 38152.512 & 128103.2 & 102898 & 0.0080631 \\
\hline $\mathrm{a}$ & $X_{\mathrm{fr}}$ & $\mathrm{y}_{0}$ & $\mathrm{Y}_{\text {head }}$ & $\mathrm{y}_{\text {sol }}$ & $\tau_{\text {head }}$ & $\tau_{\text {sol }}$ & $\sigma_{\text {head }}$ edge( & $\sigma_{\text {head }}^{\text {edge(in) }}$ & $\sigma_{\text {sol }}^{\text {ed }}$ & $\sigma_{\text {sol }}^{\text {edge(in) }}$ & Q \\
\hline 0.841489 & 95.0634 & 0.10676 & 0.206452 & 0.0739753 & 749.85 & 404.454 & 2338.579 & -2338.579 & 355.525 & -355.525 & 3483.904 \\
\hline \multicolumn{12}{|c|}{ R-65, KPP-5, Diagram 1840, e=-1 cm, $\mathrm{P}=16350 \mathrm{~kg}, \mathrm{H}=7000 \mathrm{~kg}, \mathrm{P} / \mathrm{H}=2.336, \mathrm{f}=0.32 \delta=3.85$} \\
\hline $\mathrm{U}_{\mathrm{z}}$ & $\mathrm{k}_{\mathrm{z}}$ & $\mathrm{U}_{\mathrm{y} 0}$ & $\mathrm{k}_{\mathrm{y} 0}$ & $\mathrm{U}_{\mathrm{y}}(\mathrm{fr})$ & $\mathrm{k}_{\mathrm{y}}(\mathrm{fr})$ & $\beta_{\varphi}$ & $\beta_{\varphi(\mathrm{fr})}$ & $\mathrm{U}_{\varphi}$ & $\mathrm{U}_{\varphi}(\mathrm{fr})$ & $\mathrm{M}_{\text {tor }}^{\mathrm{ex}}$ & $\varphi_{0}(\mathrm{fr})$ \\
\hline 692 & 0.0123478 & 349.472 & 0.0164538 & 877.925 & 0.0207146 & 6964421.126 & 10281756.05 & 38152.512 & 83154.8689 & 102898 & 0.0099648 \\
\hline $\mathrm{a}$ & $X_{\text {fr }}$ & $\mathrm{y}_{0}$ & $\mathrm{y}_{\text {head }}$ & $\mathrm{y}_{\mathrm{sol}}$ & $\tau_{\text {head }}$ & $\tau_{\text {sol }}$ & $\sigma_{\text {head }}^{\text {edge(ex) }}$ & $\sigma_{\text {head }}^{\text {edge(in) }}$ & $\sigma_{\text {sol }}^{\text {edge(ex) }}$ & $\sigma_{\text {sol }}^{\text {edge(in) }}$ & Q \\
\hline 0.80534 & 87.5008 & 0.082582 & 0.205787 & 0.0420651 & 749.85 & 404.454 & 2288.73 & -2288.73 & 255.163 & -255.163 & 3483.904 \\
\hline \multicolumn{12}{|c|}{$\mathrm{R}-50, \mathrm{~KB}$, Diagram 1840, e $=-1 \mathrm{~cm}, \mathrm{P}=16350 \mathrm{~kg}, \mathrm{H}=7000 \mathrm{~kg}, \mathrm{P} / \mathrm{H}=2.336, \mathrm{f}=0.3, \delta=2.372$} \\
\hline $\mathrm{U}_{\mathrm{z}}$ & $\mathrm{k}_{\mathrm{z}}$ & $\mathrm{U}_{\mathrm{y} 0}$ & $\mathrm{k}_{\mathrm{y} 0}$ & $\mathrm{U}_{\mathrm{y}}(\mathrm{fr})$ & $\mathrm{k}_{\mathrm{y}}(\mathrm{fr})$ & $\beta_{\varphi}$ & $\beta_{\varphi(\mathrm{fr})}$ & $\mathrm{U}_{\varphi}$ & $\mathrm{U}_{\varphi}(\mathrm{fr})$ & $\mathrm{M}_{\text {tor }}^{\mathrm{ex}}$ & $\varphi_{0}(\mathrm{fr})$ \\
\hline 0.927452 & 101.453 & 0.13759 & 0.241618 & 0.0942549 & 793.415 & 417.587 & 2493.575 & -2493.575 & 540.149 & -540.149 & 3431.704 \\
\hline \multicolumn{12}{|c|}{ R-50, D0, Diagram 1840, e =-1 cm, $\mathrm{P}=16350 \mathrm{~kg} \mathrm{H}=7000 \mathrm{~kg}, \mathrm{P} / \mathrm{H}=2.336, \mathrm{f}=0.15, \delta=2.0$} \\
\hline $\mathrm{U}_{\mathrm{z}}$ & $\mathrm{k}_{\mathrm{z}}$ & $\mathrm{U}_{\mathrm{y} 0}$ & $\mathrm{k}_{\mathrm{y} 0}$ & $\mathrm{U}_{\mathrm{y}}(\mathrm{fr})$ & $\mathrm{k}_{\mathrm{y}}(\mathrm{fr})$ & $\beta_{\varphi}$ & $\beta_{\varphi(\mathrm{fr})}$ & $\mathrm{U}_{\varphi}$ & $\mathrm{U}_{\varphi}(\mathrm{fr})$ & $\mathrm{M}_{\text {tor }}^{\mathrm{ex}}$ & $\varphi_{0}(\mathrm{fr})$ \\
\hline 261 & 0.0111387 & 155.51 & 0.0149068 & 195.139 & 0.0157772 & 4856680.891 & 5629448.85 & 27440.714 & 36867.8677 & 83851 & 0.0148951 \\
\hline $\mathrm{a}$ & $X_{\mathrm{fr}}$ & $\mathrm{y}_{0}$ & $\mathrm{Y}_{\text {head }}$ & $\mathrm{y}_{\mathrm{sol}}$ & $\tau_{\text {head }}$ & $\tau_{\text {sol }}$ & $\sigma_{\text {head }}{ }^{\text {edge(ex })}$ & $\sigma_{\text {head }}^{\text {edge(in) }}$ & $\sigma_{\text {sol }}^{\text {edge(ex) }}$ & $\sigma_{\text {sol }}^{\text {edge(in) }}$ & Q \\
\hline 0.57964 & 60.8747 & 0.28298 & 0.426613 & 0.223147 & 793.415 & 417.587 & 2721.132 & -2721.132 & 957.336 & -957.336 & 3431.704 \\
\hline
\end{tabular}

*units of measurement of values which are resulted in the table: $X_{\mathrm{fr}}, \mathrm{y}_{0}, \mathrm{Y}_{\text {head }}, \mathrm{Y}_{\mathrm{sol}}-[\mathrm{cm}] ; \varphi_{0}(\mathrm{fr})$ - [rad]; $\mathrm{U}_{\mathrm{z}}, \mathrm{U}_{\mathrm{y} 0}, \mathrm{U}_{\mathrm{y}(\mathrm{fr})}-\left[\mathrm{kg} / \mathrm{cm}^{2}\right] ; \mathrm{U}_{\varphi}, \mathrm{U}_{\varphi(\mathrm{fr})}-[\mathrm{kg} / \mathrm{rad}]$; $\mathrm{k}_{\mathrm{z}}, \mathrm{k}_{\mathrm{y} 0}, \mathrm{k}_{\mathrm{y}(\mathrm{fr})}-[1 / \mathrm{cm}] ; \beta_{\varphi}, \beta_{\varphi(\mathrm{fr})}-[\mathrm{kg} \cdot \mathrm{cm} / \mathrm{rad}] ; \mathrm{M}^{\mathrm{ex}}$ tor $-[\mathrm{kg} \cdot \mathrm{cm}] ; \tau_{\mathrm{i}}, \sigma_{\mathrm{i}}-\left[\mathrm{kg} / \mathrm{cm}^{2}\right] ; \mathrm{Q}-[\mathrm{kg}]$.

\subsection{Additions to the Example of Calculations}

To determine the summarized normal stresses in the rail thread, taking into account the action of vertical dynamic forces $\mathrm{P}_{\mathrm{dyn}}$, it is necessary to add to the stresses in the head and sole of the rail that obtained by new method to add the results of calculations the stresses which determined by the method described in standard methodics $[4,15]$.

For example, calculations for strength according to the standard method «Rules of calculations for strength...» [4] 
that we made at KIZT DUIT give the following results of stresses in rails for the design of track structures with rails R65 on reinforced sleepers with $\mathrm{KB}$ type fasteners under the action of 4-axle freight car CNII-HZ-0 with static load on the wheel $P_{s t}=11620 \mathrm{~kg}$ when moving in a curve $R=800 \mathrm{~m}$ with speed $V=90 \mathrm{~km} / \mathrm{h}$ and under the action of dynamic vertical force from the wheel $P_{s t}=16350 \mathrm{~kg}$ :

$$
\begin{gathered}
\sigma_{\text {head axial }}=-1030 \mathrm{~kg} / \mathrm{cm}^{2} ; \sigma_{\text {sol axial }}=+790 \mathrm{~kg} / \mathrm{cm}^{2} ; \\
\sigma_{\text {head edge }}=-1138 \mathrm{~kg} / \mathrm{cm}^{2} ; \sigma_{\text {sol edge }}=+1010 \mathrm{~kg} / \mathrm{cm}^{2} .
\end{gathered}
$$

Calculations by the new method (look the table 3 ) are given the following results of stresses in the rails:

For the same design railway track with rails R65 on reinforced concrete sleepers under the same lateral horizontal forse $H_{d y n}=7000 \mathrm{~kg}$ (and when the same vertical force $P_{d y n}=16350 \mathrm{~kg}$ takes into account only for bending torsion):

at eccentricity $\mathrm{e}=0 \mathrm{~cm}$ :

$$
\begin{gathered}
\sigma_{\text {head }}^{\text {edge }(\text { in })}=-2063 \mathrm{~kg} / \mathrm{cm}^{2} ; \sigma_{\text {head }}^{\text {edge }(e x)}=+2063 \mathrm{~kg} / \mathrm{cm}^{2} ; \\
\sigma_{\text {sole }}^{\text {edge }(\text { in })}=-493 \mathrm{~kg} / \mathrm{cm}^{2} ; \sigma_{\text {sole }}^{\text {edge }(e x)}=+493 \mathrm{~kg} / \mathrm{cm}^{2} ;
\end{gathered}
$$

at eccentricity $\mathrm{e}=-1 \mathrm{~cm}$ :

$$
\begin{gathered}
\sigma_{\text {head }}^{\text {edge(in })}=-2338 \mathrm{~kg} / \mathrm{cm}^{2} ; \sigma_{\text {head }}^{\text {edge }(e x)}=+2338 \mathrm{~kg} / \mathrm{cm}^{2} ; \\
\sigma_{\text {sole }}^{\text {edge }(i n)}=-356 \mathrm{~kg} / \mathrm{cm}^{2} ; \sigma_{\text {sole }}^{\text {edge }(e x)}=+356 \mathrm{~kg} / \mathrm{cm}^{2} .
\end{gathered}
$$

The summation of normal stresses in the lateral edges of the head and sole of the rail from the lateral bending (calculated by the new method table 3 ), and from vertical bending by the force $P_{d y n}$ (calculated by standard methods (for example [4]), in this case it is necessary to take only axial stresses in the head and in the sole of the rail) give the following final results: at eccentricity $\mathrm{e}=0 \mathrm{~cm}$ :

$$
\begin{gathered}
\sigma_{\text {head }}^{\text {edge(in) }}=-2063-1030=-3093 \mathrm{~kg} / \mathrm{cm}^{2} ; \\
\sigma_{\text {head }}^{\text {edge(ex) }}=+2063-1030=+1033 \mathrm{~kg} / \mathrm{cm}^{2} ; \\
\sigma_{\text {sole }}^{\text {edge }(\mathrm{in})}=-493+790=+297 \mathrm{~kg} / \mathrm{cm}^{2} ; \\
\sigma_{\text {sole }}^{\text {edge }(e x)}=+493+790=+1283 \mathrm{~kg} / \mathrm{cm}^{2} ;
\end{gathered}
$$

at eccentricity $\mathrm{e}=-1 \mathrm{~cm}$ :

$$
\begin{gathered}
\sigma_{\text {head }}^{\text {edge(in })}=-2338-1030=-3368 \mathrm{~kg} / \mathrm{cm}^{2} ; \\
\sigma_{\text {head }}^{\text {edge }(e x)}=+2338-1030=+1308 \mathrm{~kg} / \mathrm{cm}^{2} \\
\sigma_{\text {sole }}^{\text {edge(in })}=-356+790=+434 \mathrm{~kg} / \mathrm{cm}^{2} \\
\sigma_{\text {sole }}^{\text {edge }(e x)}=+356+790=+1146 \mathrm{~kg} / \mathrm{cm}^{2}
\end{gathered}
$$

Another example for track structure with P50 rails with DO type fasteners on wooden sleepers under the action of the same 4-axle freight car CNII-HZ-0 with the same static and dynamic load on the wheel $P_{s t}=11620 \mathrm{~kg}$ and $P_{d y n}=16350 \mathrm{~kg}$, when moving in a curve $R=600 \mathrm{~m}$ with speed $V=80 \mathrm{~km} / \mathrm{h}$ give the following results of stresses in the rails:

According to the standard method of «Rules of calculations for strength...» [4], (calculations were made by prof. M. P. Smirnov (PGUPS, Russia) [3]:

$$
\begin{gathered}
\sigma_{\text {head axial }}=-1614 \mathrm{~kg} / \mathrm{cm}^{2} ; \sigma_{\text {sol axial }}=+1302 \mathrm{~kg} / \mathrm{cm}^{2} ; \\
\sigma_{\text {head edge }}=-1844 \mathrm{~kg} / \mathrm{cm}^{2} ; \sigma_{\text {sol edge }}=+1732 \mathrm{~kg} / \mathrm{cm}^{2} .
\end{gathered}
$$

Calculations by the new method (look the table 3 ) for the same track structures design with R50 rails on wooden sleepers under the action of the same freight car at the same value of vertical dynamic force $P_{d y n}=16350 \mathrm{~kg}$ (here vertical force takes into account only for bending torsion) and under the action of lateral dynamic force $H_{d y n}=7000 \mathrm{~kg}$, are given the following results of stresses in the rails (at eccentricity e $=0$ ):

$$
\begin{aligned}
& \sigma_{\text {head }}^{\text {edge(in })}=-2398 \mathrm{~kg} / \mathrm{cm}^{2} ; \sigma_{\text {head }}^{\text {edge }(e x)}=+2398 \mathrm{~kg} / \mathrm{cm}^{2} ; \\
& \sigma_{\text {sole }}^{\text {edge }(i n)}=-1151 \mathrm{~kg} / \mathrm{cm}^{2} ; \sigma_{\text {sole }}^{\text {edge }(e x)}=+1151 \mathrm{~kg} / \mathrm{cm}^{2} \text {. }
\end{aligned}
$$

The summation of normal stresses in the lateral edges of the head and sole of the rail from the lateral bending (calculated by the new method in table 3 ), and from vertical bending by the force $P_{d y n}$ (calculated by standard methods (for example [4]), in this case it is necessary to take only axial stresses in the head and in the sole of the rail) give the following final results:

$$
\begin{aligned}
& \sigma_{\text {head }}^{\text {edge(in) }}=-2398-1614=-4012 \mathrm{~kg} / \mathrm{cm}^{2} ; \\
& \sigma_{\text {head }}^{\text {edge }(e x)}=+2398-1614=+784 \mathrm{~kg} / \mathrm{cm}^{2} ; \\
& \sigma_{\text {sole }}^{\text {edge }(i n)}=-1151+1302=+151 \mathrm{~kg} / \mathrm{cm}^{2} ; \\
& \sigma_{\text {sole }}^{\text {edge }(e x)}=+1151+1302=+2453 \mathrm{~kg} / \mathrm{cm}^{2} .
\end{aligned}
$$

\section{Conclusion}

The results of the researches performed and comparative computer calculations to determine the maximum stresses and strains from vertical and lateral bending and torsion in rail threads with rails of different types R65, R50, 60E1 (UIC60) with different designs of rail supports (reinforced concrete or wooden sleepers) and various designs of rail fasteners showed the following:

1) The proposed new calculation method (in which the influence of lateral horizontal forces $H_{\text {din }}$ and torque moment $M_{\text {tor }}^{e x}$ from the forces $P_{d i n}$ and $H_{d i n}$ is taken into account directly by the calculation) gives significantly more correct results on stresses and deformations in rails under conditions of dynamic interaction of the track and rolling stock, and especially in the curves sections;

2) Strength calculations using standard methods of the "Rules 
of design..." [2, 3, 4] (in this case, the action of horizontal forces is taken into account by means of the so-called "influence coefficients" $\mathrm{f}$ ") give significant errors in the values of maximum stresses in the edges of rail head and sole:

a) Accordingly, for R65 rails on reinforced concrete sleepers:

for the external edge of the head 1.9-2.15 times

for the internal edge of the head 2.7-2.9 times

for the external edge of the sole by 1.27-1.3 times

for the internal edge of the sole 3.4-2.3 times

b) Accordingly, for R50 rails on wooden sleepers:

for the external edge of the head 3.35 times

for the internal edge of the head 2.17 times

for the external edge of the sole by 1.4 times

for the internal edge of the sole by 11.5 times

3 ) It is obvious that strength calculations of rail threads using standard methods [2, 3, 4] (in which vertical rail bending is considered as a beam on an elastic foundation) give correct results only for determining axial normal stresses in the rail head and sole. The use of the so-called influence factors "f" (in their current form) cannot be recommended for determining the stresses in the edges of the rail head and sole, because they require correction.

Besides, calculations using standard methods [2, 3, 4] (except of experimental research methods $[5,20,21,22])$ generally do not provide the possibility of obtaining the results of transverse horizontal deformations of rail threads and torsional deformations of their cross sections under the combined action of forces Pdin, Hdin and torque moment $M_{t o r}^{e x}$.

\section{References}

[1] Shakhunyants G. M. Zheleznodorozhniy put [Railway track]. Moscow, Transport Publ., 1987. 479 p.

[2] Verigo M. F., Krepkogorskiy S. S. Obshchiye polozheniya dlya korrektirovki «Pravil raschetov zheleznodorozhnogo puti na prochnost» [General provisions for adjusting the «Rules of calculation of railway track for strength»]. Trudy Vserossiyskogo nauchno-issledovatelskogo instituta zheleznodorozhnogo transporta [Proc. of All-Russian Research Institute of Railway Transport], Moscow, 1972, issue 466, pp. 4-50.

[3] Smirnov M. P. Osnovy rascheta jelementov verhnego stroenija puti na prochnost' [Basics of strength calculation of track superstructure elements] in the book: "Osnovy ustrojstva i raschetov zheleznodorozhnogo puti" [Fundamentals of the device and calculations of the railway track]. Moscow, Transport Publ., 1990. pp. 264-318.

[4] Pravyla rozrakhunkiv zaliznychnoi kolii na mitsnist' i stijkist' [Rules for calculating the railway track for strength and stability] under editor Danilenko E. I. Kyiv, Transport of Ukraine, 2006. 168 p.

[5] Danilenko E. I., Velinets V. P. Eksperymentalni doslidzhennia kharakterystyk horyzontalnoi poperechnoi zhorstkosti i modulia pruzhnosti zaliznychnoi kolii pry riznykh konstruktsiiakh reikovykh skriplen [Experimental studies of characteristics of horizontal and lateral stiffness and elasticity modulus of railway track in various designs of rail fasteners]. Zaliznychnyi transport Ukrainy - Railway Transport of Ukraine, (Journal) 2015, no. 4, pp. 3-11.
[6] Danilenko E. I. Raschet harakteristik zhestkosti i uprugosti rel'sovoj niti pri kruchenii pod vozdejstviem vertikal'nyh i gorizontal'nyh sil [Calculation of the characteristics of stiffness and elasticity of a rail thread in torsion under the influence of vertical and horizontal forces]. Nauka ta prohres transportu. Visnyk Dnipropetrovs'koho natsional'noho universytetu zaliznychnoho transportu [Science and progress of transport. Bulletin of Dnipropetrovsk National University of Railway Transport], 2016, issue 5 (65), pp. 79-91.

[7] Danilenko E. I., Molchanov V. M., Danilenko T. P. Zminnist' pruzhnozhorstkisnykh kharakterystyk bokovoho zghynu ta kruchennia rejkovoi nytky zalezhno vid spivvidnoshennia kolisnykh navantazhen' Pdyn/Hdyn [Variability of elastic-rigid characteristics of lateral bending and torsion of rail thread depending on the ratio of wheel loads Pdin/Hdin]. Zbirnyk naukovykh prats' Ukrains'koho derzhavnoho universytetu zaliznychnoho transportu [Proc. of scientific works of the Ukrainian State University of Railway Transport], Kharkiv, 2018 , issue 179 , pp. 66-82.

[8] Timoshenko S. P. Metod issledovaniy statisticheskikh i dinamicheskikh napryazheniy $\mathrm{v}$ relse [Method of research of statistical and dynamic stresses in the rail]. Statisticheskiye $i$ dinamicheskiye problemy teorii uprugosti [Statistical and dynamic problems of the elasticity theory]. Kyiv, Science Publ., 1975, pp. 209-220.

[9] Timoshenko S. P. Napryazheniya v zheleznodorozhnom relse [Stresses in the rail]. Statisticheskiye i dinamicheskiye problemy teorii uprugosti [Statistical and dynamic problems of the elasticity theory]. Kyiv, Science Publ., 1975, pp. 318-355.

[10] Stepkin S. A. O mestnyh naprjazhenijah v rel'sah pri kruchenii [About local torsional stresses in rails] Sbornik trudov Leningradskogo institutu inzhenerov transporta [Proceedings of the Leningrad Institute of Transport Engineers], 1937, issue 127.

[11] Golovanov D. G. Vlijanie modulja uprugosti osnovanija rel'sa $\mathrm{v}$ otnoshenii kruchenija na naprjazhenija i deformacii v rel'se, zagruzhennom poperechnoj gorizontal'noj siloj [Influence of the modulus of elasticity of the rail base in relation to torsion on stresses and deformations in a rail loaded with a lateral horizontal force]. Trudy Tashkentskogo instituta inzhenerov transporta [Proceedings of the Tashkent Institute of Transport Engineers], 1956, issue V.

[12] Golovanov D. G. Vlijanie modulja uprugosti osnovanija rel'sa $\mathrm{v}$ otnoshenii izgiba na deformacii i naprjazhenija v rel'se, zagruzhennom poperechnoj gorizontal'noj siloj [Influence of the modulus of elasticity of the rail base in relation to bending on deformations and stresses in a rail loaded with a lateral horizontal force]. Trudy Tashkentskogo instituta inzhenerov transporta [Proceedings of the Tashkent Institute of Transport Engineers], 1954, issue IV.

[13] Yershkov O. P. Kharakteristiki prostranstvennoy uprugosti relsovoy niti [Characteristics of the spatial elasticity of rail thread]. Trudy Vserossiyskogo nauchno-issledovatelskogo instituta zheleznodorozhnogo transporta [Proc. of All-Russian Research Institute of Railway Transport], Moscow, 1960, issue 192, pp. 59-101.

[14] Yershkov O. P. Raschet relsa na deystviye bokovykh sil v krivykh [Rail Calculation of the rail under the action of the lateral forces in the curves]. Trudy Vserossiyskogo nauchno-issledovatelskogo instituta zheleznodorozhnogo transporta [Proc. of All-Russian Research Institute of Railway Transport], Moscow, 1960, issue 192, pp. 5-59. 
[15] Proektuvannia i rozrakhunky konstruktsij zaliznychnoi kolii (Tom 2). [Design and calculations of railway structures] under editor Danilenko E. I. Kyiv, Hi-Tech Press Publ., 2020. $552 \mathrm{p}$.

[16] Timoshenko S. P. K voprosu o prochnosti rels [To the question about rail strength] in the book: "Prochnost i kolebaniya elementov konstruktsiy" [Strength and vibration of construction elements], Moscow, Science Publ., 1975, pp. 322-358.

[17] Spravochnik inzhenera-puteytsa. (Tom 1). [Reference of a railway engineer], under editors Basilov V. V., Chernyshev M. A. Moscow, Transport Publ., 1972. 767 p.

[18] Shakhunyants G. M. Zheleznodorozhniy put [Railway track]. Moscow, Transport Publ., 1969. 536 p.

[19] Feodosyev V. I. Soprotivleniye materialov [Resistance of materials]. Moscow, Science Publ., 1970. 544 p.
[20] Liu, C., Zeng, Z. P., Wu, B., Yuan, J. Y., He, X. F. Experimental Study on the Transverse Stiffness of WJ-8 Rail Fastening. Applied Mechanics and Materials, vol. 596, Trans Tech Publications, Ltd., July 2014, pp. 3-6.

[21] Koc W, Wilk A, Chrostowski P, Grulkowski S. Tests on lateral resistance in railway tracks during the operation of a tamping machine. Proceedings of the Institution of Mechanical Engineers, Part F: Journal of Rail and Rapid Transit. 2011, vol. 225, issue 3, pp. 325-340.

[22] Darenskiy O. M., Tuley Yu. L., Ovchynnikov O. O., Leibuk Ya. $\mathrm{S}$. Numerical investigations of dynamic transverse forces in curves, in the zones of rail varieties. Proc. of scientific works of Ukrainian State University of Railway Transport. Kharkiv, 2018, issue 179, pp. 51-58. 